\title{
Diurnal Variations of Warm Season Rainfall Affected By Complex Topography Based On High-Density Stations Observation In Chongqing Over Southwest China
}

\section{Qiang Li ( $\nabla$ cqlqlq@163.com )}

Chongqing meteorological observatory https://orcid.org/0000-0002-5596-1306

\section{Yongguang Zheng}

National Meteorological Centre

\section{Guobing Zhou}

Chongqing meteorological observatory https://orcid.org/0000-0002-4777-9483

\section{Yan Zhu}

Chongqing meteorological observatory

Chao Liu

Chongqing meteorological observatory

\section{Research Article}

Keywords: warm season, complex topography, diurnal variation, Southwest China

Posted Date: August 10th, 2021

DOI: https://doi.org/10.21203/rs.3.rs-761678/v1

License: (c) (1) This work is licensed under a Creative Commons Attribution 4.0 International License.

Read Full License 


\section{Abstract}

Located in the eastern edge of the Sichuan Basin (SCB) in the southwest China, Chongqing is a mountainous region with typical complex topographic features. Using the hourly precipitation observation data of high-density 1686 meteorological stations in Chongqing during warm season from 2009 to 2016, the diurnal characteristics of precipitation effected by complex topography are investigated. The mountainous terrain has a significant impact on distinct regional features of rainfall amount, frequency, and intensity, and stations located in the higher complex mountainous areas are larger than those in the lower surrounding areas. In addition, the detailed characteristics of the rainfall amount and frequency over four study regions further show that the values at higher elevations are larger than those at the lower elevations, and the rainfall amount and frequency significantly increase, especially in the area that terrain heights sharply increase along mountains extending direction. The diurnal characteristics of the rainfall amount has dual structure with a dominant early-morning peak appearing at approximately 0700 LST (23 UTC), and a weaker secondary late-afternoon peak is found at approximately 1600 LST (08 UTC). The rainfall amount and frequency peaks during early-morning accounts for $81.9 \%$ and $88.1 \%$ of all stations, respectively. However, the rainfall frequency has single early-morning peak diurnal characteristics. The gauge elevation has a significant impact on the diurnal variations of the early-morning rainfall. With elevation increasing in four study regions, the proportions of the rainfall amount (frequency) that occurs during early-morning periods decrease. Different duration hours of rainfall events have distinct diurnal variation and phase features.

\section{Introduction}

The complex topography play a significant role in heterogeneous spatial and temporal distributions of rainfall patterns, and most previous researches have shown that the mechanisms of orographic influences on rainfall are complex (Smith,1979; Jiang and Smith,2003;Colle,2004; Smith and Barstad, 2004;Roe, 2005; Rotunno and Houze, 2007; Kirshbaum, 2011;Houze, 2012; Couto et al., 2016; DeHart and Houze, 2017; Purnell and Kirshbaum, 2018;Kang,2019). Many features of mountainous topography, including elevation, relief amplitude, slope, and aspect, can initiate, enhance, and modify rainfall, and further influence diurnal and spatial variations of rainfall (Weisse and Bois, 2001; Burbank et al., 2003; Lee et al.,2010; Chen et al., 2013; White and Paul,2015;Kirshbaum et al., 2018; Sarmadi et al., 2019). Among the orographic and morphological characteristics, elevation differences considerably perform an important function in the spatial variation of climatic rainfall in mountainous regions (Basist et al., 1994; Goovaerts, 2000; Johansson and Chen, 2003; Sokol and Bližňák, 2009;Silverman et al., 2013).

The topography in China are complex and various with diverse mountain ranges and plateaus, therefore the influence of terrain on precipitation is more complex (Tao,1980; Peng et al., 1995; Liao et al., 2007;Yu et al.,2014). Due to the forcing effects of spatial scale and height differences of complex topography, the spatiotemporal characteristics of precipitation demonstrate fairly obvious regional differences (Wang et al., 2013;Li et al.,2017b;Yu et al.,2018;Li et al.,2019;Li et al.,2020). The Tibetan Plateau (TP) is the highest topographic region, and influences of its size and shape on rainfall are not only closely related to spatial 
distributions of rainfall between the local and the surrounding areas (Liu et al.,2009; Xu and Zipser,2011; Jin et al., 2013; Guo et al.,2014;Guo et al.,2016;Cuo and Zhang, 2017;Li,2017a;Chen at al.,2018), but also to diurnal variations east of the TP over China (Bao et al.,2011;Zhang et al.,2014a,b;Wang et al.,2018). However, regional topography only force local circulations that affect the local features of diurnal variation (Barros and Lang, 2003;Chen et al., 2012; Li et al., 2017).The locally enhanced convergence in the Dabie Mountains provides the strongest thermal and dynamic forcing lifting that initiates the earliest convective cells, which leads to condensation and formation of the morning precipitation peak(Tang et al., 2012,Wang et al.,2016;Fu et al.,2019). Li et al. (2019) reveals influences of the gauge elevations on the diurnal variation of rainfall, and the proportion of the rainfall frequency occurring during the early-morning period decreases with increasing elevations over the Qilian Mountains. Gan et al. (2019) proposes that typical small-scale Mount Tai exhibits great differences in precipitation characteristics with a large enhancement effect on rainfall, which is different from the surrounding areas. These studies show that the isolated mountainous topography plays a crucial role in spatial and temporal variation of precipitation. However, the details about the spatial variation of precipitation over complex topography are not consistent, especially for the possible links between mountainous features and precipitation over different areas of complex topography.

In recent years, with the appearance of multiyear continuous hourly rainfall data, an increasing number of studies have focused on the diurnal cycles of the rainfall characteristics in many regions around the world(Leahy and Kiely,2011;Deshpande et al.,2012; Hitchens et al.,2013;Stevenson and Schumacher,2014; Iwasaki,2012,2015). Similar researches on diurnal variations of precipitation based on hourly rainfall data have also made great progress over mainland China(Yu,2007a,2007b,2014; Chen et al., 2015;Liang and Ding, 2017; Li et al., 2017). Using a long-term dataset comprising measurements made at more than 2420 stations over SCB, Zheng et al. (2016) finds that the SCB experienced higher rainfall accumulations and a higher occurrence of short-duration heavy rainfall events compared with other subregions of China. Based on the same datasets, Luo et al. (2016) reports that extreme hourly rainfall over SCB peaks in July. Furthermore, based on daily precipitation data from 524 observation stations, Zhang C et al. (2019) reveals that, on the regional scale, some differences exist in the changes of autumn rainfall between the eastern and the western parts of West China. In addition, based on hourly rainfall data of 468 rain gauge stations, Chen et al. (2021) studies spatial and temporal characteristics of abrupt heavy rainfall (AHRE) events over southwest, and the occurrence frequency of these AHRE exhibits large spatial variability among different regions. Nevertheless, the previous studies used observations at the limited automatic meteorological stations and lacked precipitation data with a higher spatial resolution, their results show some regional differences on precipitation diurnal variations over China. Due to the sparse gauge networks and the large spatial and temporal variations of rainfall, obtaining accurate finding has been challenging for scientists especially in complex terrain.

Located close to the eastern edge of SCB in the southwest China (Fig.1a), Chongqing (105 $11^{\prime} \sim 110^{\circ} 11^{\prime}$ $\mathrm{E}, 28^{\circ} 10^{\prime} \sim 32^{\circ} 13^{\prime} \mathrm{N}$ ) is a mountainous region in the middle and upper reaches of the Yangtze River, and has a humid subtropical monsoon climate zone affected by the TP significantly. Chongqing, known as "mountain city", has special geographical conditions with relatively flat terrain in the Sichuan Basin and 
mountains along the edge of the basin. Recently, considerable studies have been conducted to reveal the effects of orography on diurnal variation of nocturnal precipitation peak time over SCB (Zhang et al.,2014a;Chen et al., 2017; Xue et al., 2018). In addition, the movement of precipitation over the SCB and the adjacent regions is closely tied to multiple regional-scale mountain-plain solenoids because of the great contrast in terrain heights between the SCB and surrounding mountain ranges (Qian et al., 2015). Zhang Y et al. (2019) demonstrates that prominent diurnal inertial oscillations of south-southwesterly low-level jet into the southeast side of the SCB play an important role in modulating the diurnal variation of precipitation over the SCB. Li et al. (2020) finds there is a prominent northeastward time delay of precipitation peak over the SCB, and the diurnal variation of $850 \mathrm{hPa}$ wind has strong easterly wind deviations in the early evening, which favors for an initiation of precipitation by orographic lift of air. However, few studies have reported on the rainfall diurnal cycle in Chongqing, especially achievement between rainfall and terrain. Using the hourly precipitation data observed at 34 gauge stations in Chongqing, Chen et al. (2019) reveals the spatial and temporal characteristics of the precipitation. By selecting 16 representative stations in two types of terrain for analysis, the results show that the amplitude of diurnal precipitation at the stations in higher terrain is weaker. The studies yielded somewhat significant results in this area. Nevertheless, derived from rare stations, studies cannot be conducted to analyze the detailed characteristics of rainfall over the complex topography in Chongqing. Hence, more thorough researches need to be carried out on the diurnal variation of precipitation based on hourly precipitation observed from automatic meteorological stations and high-density regional meteorological stations.

In this study, based on high-density and quality-controlled hourly rain-gauge data, detailed spatiotemporal evolutions of rainfall amount, frequency, intensity, and durations in the different topographic areas over Chongqing is investigated. In addition, the relationships between the diurnal characteristics and the complex topography will also be revealed. The structure of this paper is organized as follows. Section 2 describes study region, the datasets and analysis methods. Section 3 shows the detailed spatial-temporal distributions features of rainfall, the detailed characteristics of diurnal evolution, and the relations between early-morning rainfall and the elevation. Finally, conclusion and discuss is given in section 4 .

\section{Study Region, Data And Methods}

\subsection{Description of the study area}

Chongqing is one of the most typical complex topographic features located in an inland area, which is the transitional region between the second and third topography steps of China (Fig. 1a). The west Chongqing goes deep into the SCB at low elevation while the east Chongqing gradually rises eastward with high terrain spreading on Wu Mountain (WM) and reaches the middle of the Yangtze River. The south Chongqing is adjacent to Dalou Mountains (DLM) and Wuling Mountains (WLM), and the north Chongqing lays back the Daba Mountains (DBM). The topography inclines from the west toward the Yangtze River valley and can be divided into the following categories: plains, hills, mid-height mountains, and tablelands. The mountains, hills, tablelands, and plains account for $75.9 \%, 17.0 \%, 3.57 \%$, and $2.39 \%$, 
respectively, of the total land area (Chongqing Bureau of Geology and Minerals Exploration (CBGM) 2002).

Figure 1c shows numbers of station at different terrain height. Initially, the numbers rapidly increase from 100 to 250 m with maximum value reaching between 200 and $500 \mathrm{~m}$ (62.6\% of all stations), and then gradually reduce from 500 to $1600 \mathrm{~m}$. The proportions of stations below 500 and below $1000 \mathrm{~m}$ to total stations are $64.7 \%$ and $93.0 \%$, respectively.

Because of the complex terrain, in order to illustrate the detailed features of rainfall and to facilitate further obtaining links between mountainous features and rainfall over different areas in Chongqing, we select four typical areas by considering the topographical features, as are shown by red boxes in Fig. 1b. The northwestern study area (NW) denotes the complex topography of mixed basin and hills, and the southwestern study area (SW) is the mountainous terrain in southwest Chongqing adjacent to the northern DLM. The southeastern study area (SE) represents mountainous terrain in southeast Chongqing and the northeastern study area (NE) is mountainous terrain in northeast in which the DBM lays. The numbers of stations in NW, SW, SE, and NE are 149,145,111, and 141 stations, respectively. The statistics of station heights in every area are shown in Fig. 1d. The average elevation gradually increases from $359.7 \mathrm{~m}$ in the NW to $693.8 \mathrm{~m}$ in the NE. Meanwhile, the lower quartile, median, and upper quartile values of terrain height also increase, ranging from 261, 312.3, and $416 \mathrm{~m}$, respectively, in the NW, to 394, 683.9, and $881 \mathrm{~m}$, respectively, in the NE sub-region. In addition, for each area in Fig. 1d, the maximum height is high, especially in the SW (1350 m), SE (1267 m), and NE (1723 m) above $1000 \mathrm{~m}$. The minimum height of each area is comparatively close, which indicates that there are greater terrain height variations in every area. This variation is mainly brought by the underlying surface variation of complex terrain, especially in the SW and NE.

\subsection{Station data and Data processing}

The hourly rain gauge observations data were obtained from the National Meteorological Information Centre (NMIC) of the China Meteorological Administration, which includes a total of 1686 surface automatic weather stations (Fig. 1b) and covers the entire warm season (May-September) from 2016 to 2020 in Chongqing. This dataset has undergone strict quality control (extreme value checks, internal consistency checks, and time consistency checks), rendering it appropriate for studying the effect of complex topography on precipitation. To minimize the impact of missing values on the analysis, for the hourly precipitation data, the missing data must be less than $1 \%$ of the total records for 5 years series, and every station has more than 17370 hours without missing or suspicious values. Although the reconstruction is necessary for guaranteeing the completeness of the dataset and for raising the statistical confidence, we find that there is little difference between the analysis results through a comparison of the reconstructed and unreconstructed data.

\section{3 methods}

In this study, following the previous studies (Dai et al., 1999; Liang et al., 2004; Yu et al., 2007a, 2007b; Zhou et al., 2008), the definitions of the four rainfall features in this study are depicted as follows. 
(1) Rainfall amount: cumulative amount with measurable rainfall (rainfall rate $\geq 0.1 \mathrm{~mm} \mathrm{~h}^{-1}$ ) divided by the number of non-missing hours during the study period.

Rainfall amount $\left(\mathrm{mm} \mathrm{h}^{-1}\right): \mathrm{P}_{\mathrm{r}} / \mathrm{N}_{\mathrm{nm}}$

(2) Rainfall frequency: cumulative total hours with measurable rainfall (rainfall rate $\geq 0.1 \mathrm{~mm} \mathrm{~h}^{-1}$ ) divided by the number of non-missing hours during the study period.

Rainfall frequency (\%): $\mathrm{N}_{\mathrm{r}} / \mathrm{N}_{\mathrm{nm}}$

(3) Rainfall intensity: cumulative rainfall divided by the number of rainy hours during the study period.

Rainfall intensity $\left(\mathrm{mm} \mathrm{h}^{-1}\right): \mathrm{P}_{\mathrm{r}} / \mathrm{N}_{\mathrm{r}}$

$P_{r}$ is the accumulated rainfall amount with measurable rainfall during the study period, $N_{n m}$ is the number of hours with no missing rainfall records, and $\mathrm{N}_{\mathrm{r}}$ is the number of hours with measurable rainfall.

(4)Rainfall event: the starting time of a rainfall event is defined as the time there is no rainfall in the previous two or more than two hours before measurable rainfall event $\left(\geq 0.1 \mathrm{~mm} \mathrm{~h}^{-1}\right)$ occurs. The ending of a rainfall event is defined as the time there is no rainfall in the next two or more than two hours after measurable rainfall event $\left(\geq 0.1 \mathrm{~mm} \mathrm{~h}^{-1}\right)$ occurs. The numbers of rainfall events are defined as the accumulated numbers of the total rainfall events during the whole warm season precipitation period. The duration time (rainfall amount) is defined as the hours (accumulated rainfall amount) between the starting and the ending of a rainfall event, during which there is no interruption or only a 1-h interruption. The most frequent starting time of rainfall events is considered as the time when the most frequent hour rainfall events occur, and the most frequent peaking and ending time are defined similarly.

For each type of rainfall events, let $R_{a}(h)$ represent the amount of hourly rainfall at time $\mathrm{h}$. The normalized diurnal variation of precipitation, $D_{a}(h)$, is calculated by

$D_{a}(h)=\left(\frac{R_{a}(h)}{\frac{1}{24} \sum_{i=1}^{24} R_{a}(i)}-1\right)$

The $R_{a}(h)$ is resulted from an average of the rainfall events with a specific duration. Since warm season rainfall accounts for approximately $85 \%$ of the annual rainfall, this study focuses on warm season.

\section{Results}

\subsection{Spatial characteristics of warm season rainfall in Chongqing}


The spatial distributions of warm season rainfall amount, frequency, and intensity in Chongqing are shown in Fig. 2, which have distinct differences for stations with different gauge elevations. As illustrated in Fig. 2a, the spatial distributions of the rainfall amount are apparently heterogeneous. The average rainfall amount at elevations below $500 \mathrm{~m}$, between 500 and $1000 \mathrm{~m}$, and above $1000 \mathrm{~m}$ is $0.21 \mathrm{~mm} \mathrm{~h}^{-1}$, $0.23 \mathrm{~mm} \mathrm{~h}^{-1}$, and $0.25 \mathrm{~mm} \mathrm{~h}^{-1}$, respectively. Large rainfall amount value stations, i.e., those above 0.21 $\mathrm{mm} \mathrm{h}^{-1}$, appear over the northern sections of DLM, the southern sections of DBM, the southern sections of WLM, and mountainous areas in the southeast Chongqing. On the contrary, small value stations of rainfall amount are located in most of the central and the western regions, and the eastern and southern sections of the northeast Chongqing. It should not be ignored that scattered stations of large rainfall amount values locate in Huarong Mountain in the NW.

The distribution patterns of frequency (Fig. 2b) are consistent with the rainfall amount. The average rainfall frequency of below $500 \mathrm{~m}$, between 500 and $1000 \mathrm{~m}$, and above $1000 \mathrm{~m}$ is $0.13,0.14$, and 0.17 , respectively. The ratios of stations rainfall amount exceeding $0.21 \mathrm{~mm} \mathrm{~h}^{-1}(89 \%)$ and frequencies exceeding 0.13 (94\%) above $1000 \mathrm{~m}$ are approximately twice more than those below $500 \mathrm{~m}(44 \%, 46 \%)$, and the ratios are $72 \%$ and $79 \%$ between 500 and $1000 \mathrm{~m}$. In other words, it is clear that the rainfall amount and frequency over mountainous areas is much higher than that in surrounding low elevation areas.

The distribution of intensity (Fig. 2c) is slightly different from the previous two with the intensity below $500 \mathrm{~m}$, between 500 and $1000 \mathrm{~m}$, and above $1000 \mathrm{~m}$ are 1.62, 1.63, and $1.55 \mathrm{~mm} \mathrm{~h}^{-1}$, respectively. The proportions of intensity exceeding $1.55 \mathrm{~mm} \mathrm{~h}^{-1}$ are $63 \%, 64 \%$, and $45 \%$, respectively. Large values appear in the northern sections DLM, the southern sections of DBM, mountainous areas in southeast, and hilly areas in NW. It can still be found that stations with large rainfall intensity value scatter in Huarong Mountain. Compared with rainfall amount and frequency large values, the distributions of large rainfall intensity values are not entirely coincident, which do not occur at the tops of DBM and WLM but in the two slope regions. The large rainfall intensity values extend southward to the south of mountainous terrain, especially in the south DBM and the south WLM, which indicates that the terrain has a significant impact on the characteristics of precipitation. The heavy rainfall is more likely to occur in the south of the piedmont, namely the windward slope zone with the terrain interacting with the south wind, rather than the tops(Houze, 2012). The same results is found by Chen et al(2019) in this area. The spatial correlation coefficient between the rainfall amount and frequency (intensity) in large value regions of rainfall amount (exceeding $0.23 \mathrm{~mm} \mathrm{~h}^{-1}$ ) between $500 \mathrm{~m}$ and $1000 \mathrm{~m}$ is 0.73 and 0.65 , respectively. These coefficients indicate that most stations with large rainfall amount also have large rainfall frequency and intensity.

In summary, the spatial distributions of rainfall amount, frequency, and intensity have obvious regional characteristics. It is notable that the distributions of large rainfall amount, frequency and intensity values are located in the complex mountainous terrain areas, especially in four study regions we have selected.

The peak time of the rainfall factors reflects the main characteristics of diurnal variation. To describe the phase of the peak time in the diurnal variation more clearly, we divided the $24 \mathrm{~h}$ of a day into four time 
periods: night(2100-0100 LST), early-morning (0200-1000 LST), noon (1100-1300 LST), and afternoon (1400-2000 LST). Figure 3 show spatial distributions of the hourly peak over $24 \mathrm{~h}$ for the warm season rainfall amount, frequency, and intensity. The prevailing early-morning peaks (0200-1000 LST) of rainfall amount appear over the west, the middle, the most of southeast, and the parts of northeast regions in Chongqing. The ratio of early-morning peaks accounts for up to $81.9 \%$ of all stations. The late-afternoon peaks (1400-2000 LST) mainly appear over DBM ranges and WLM ranges, and the proportion of all stations is $11.8 \%$. In addition, the peak hours of rainfall in the western region (west of $107^{\circ} \mathrm{E}, 36 \%$ earlymorning peaks) occurs obviously earlier than those in the eastern region (east of $108^{\circ} \mathrm{E}, 26 \%$ ), which has been found that the eastward delayed diurnal phases downstream of the central eastern China (Yu et al.2007b).

Similar to the rainfall amount, the early-morning peaks have played dominant role for the rainfall frequency. A total of $88.1 \%$ of the stations have early-morning peaks, which distribute over the major region. The rare late-afternoon peaks (8.6\%) scatter in DBM ranges and WLM ranges. Also, it is notable that the eastward delayed diurnal phases occur mainly in the peak hours of rainfall frequency from the west to the east.

Compared with the patterns of rainfall amount and rainfall frequency, the patterns of the rainfall intensity are apparently heterogeneous. $47.0 \%$ of the total stations have early-morning peaks, which mostly distribute over the west region and southeast region.

Overall, the above results demonstrate the dominance of early-morning peaks in determining the distinct diurnal features of warm season rainfall and the characteristics of nocturnal rainfall with eastward phase transition. In accordance with the diurnal peaks showing that the nighttime rain is evident in the SCB (Yu et al.,2007a;Bao et al.,2011; Qian et al.,2015,Zhang Y et al.,2019; Li et al.,2020), the same prominent nocturnal feature is found in the SW and NW, yet the diurnal peaks isn't always consistent with the SE and NE. The west Chongqing with low terrain height is located in the eastern SCB, but the east Chongqing with high altitude complex terrain reaches the edge of SCB. We further analyze the detail characteristics of four study regions in the following chapter.

\subsection{The diurnal variation of precipitation in different area}

The general spatial features of the hourly warm season rainfall in Chongqing have been acknowledged. To recognize the diurnal variations in the warm season rainfall, Fig. 4 shows the standardized diurnal curves of the warm season rainfall amount, frequency, and intensity over four study regions.

Specifically, it can be seen that the rainfall amount have bimodal structure with a dominant early-morning peak at approximately 0700 LST (23 UTC), which appears during 02:00-10:00 LST with accounting for $57.5 \%, 55.0 \%, 48.0 \%$, and $44.2 \%$ of the total rainfall in the SW, NW, SE, and NE, respectively, and a weaker secondary late-afternoon peak at approximately 1600 LST (08 UTC), which appears over14:00-20:00 LST with accounting for $19.7 \%, 21.4 \%, 23.7 \%$, and $29.8 \%$ of the total rainfall, respectively. Similar to the diurnal variation in the SCB showing that the nocturnal rainfall is evident (Zhang Y et al.,2019), the 
difference is that the rainfall amount has two peak with the maximum peak values of the dominant earlymorning in the SW, NW, SE, and NE and the values are $0.396,0.404,0.388$, and 0.362 , respectively, higher than that of the late-afternoon, which are $0.183,0.204,0.251$, and 0.307 , respectively. Our findings differ from precious research obtained from the hourly national automatic weather stations (Chen et al. 2019), of which the results do not include more detailed regional automatic weather stations.

Different from two peak diurnal variations of rainfall amount, there is one peak diurnal characteristic of the rainfall frequency at around 0700 LST (23 UTC) during the early-morning (02:00-10:00 LST) in the SW, NW, and SE accounting for $50.3 \%, 48.1 \%$, and $43.4 \%$ of the total rainfall respectively, but there are dual peak that are the same as diurnal variations of rainfall amount in the NE. The maximum peak values of the rainfall frequency in the SW, NW, SE, and NE are $0.197,0.212,0.191$, and 0.167 , respectively.

Compared with the warm season rainfall amount and frequencies, the diurnal variations of the rainfall intensity is not very evident. There are two peaks in the SW, but it is different from the multi-peaks structure in the NW, SE, and NE with the maximum peak values located at around 0600 LST (22 UTC) over the early-morning. The detailed diurnal variation of rainfall intensity in every region is heterogeneous.

For every region, the diurnal variations of rainfall amount can be attributed to those of both the rainfall frequency and rainfall intensity. The dominant early-morning peak mainly comes from the rainfall frequency, and the weaker secondary late-afternoon peak mainly is generated due to the rainfall intensity. Especially for the NE, such a kind of rainfall is likely to occur as local convective precipitation. As noted by Liao et al. (2007), due to the diurnal variation of solar heating, the lower atmosphere tends to reach unstable state in the afternoon so that a little disturbance can trigger local convective rainfall. Yu et al. (2013) also indicated that this occurs due to the asymmetry of precipitation processes and the evolution of convective clouds.

In conclusion, it should be noted that the maximum peak time periods are relatively consistent with diurnal variation of rainfall amount, intensity, and frequency with generally reaching their maxima in the early-morning. In addition, the detailed diurnal rainfall cycles of rainfall amount and intensity is the same in the SW and NW, and that is generally consistent with the SE and NE.

From the above analysis, the dominant early-morning peak is evident. Some researchers found an increasing amount of precipitation with altitude increasing in the mountain (Giorgi et al., 1997; Liu et al., 2011; Guo et al., 2016). To quantitatively assess the relationship between the early-morning rainfall and the gauge elevation over four study regions, we study the correlation between the proportion of rainfall amount (frequency) during the early-morning period to the total daily rainfall frequency and the gauge elevation (Fig. 6). The linear fittings show that the proportion of the rainfall amount (frequency) occurring during the early-morning period is negatively correlated with the elevation in four regions. The linear correlation coefficients $(R)$ are $-0.934(-0.934),-0.880(0.886),-0.902(-0.906)$, and $-0.814(-0.814)$, respectively, which pass the significance test at the $99 \%$ confidence level, and corresponds to the proportions of early-morning rainfall amount (frequency) to the total rainfall over the higher elevations to be smaller than that of the lower elevations. This suggests that the altitude effect of the early-morning 
rainfall frequency is significant. The early-morning rainfall trend is obviously diminished with elevation increasing, which indicates the high mountainous regions experience more other periods in precipitation than that at lower elevations.

\subsection{The detailed characteristics of early-morning rainfall in four regions}

The previous results demonstrate the dominance of early-morning rainfall in determining the distinct diurnal features of warm season rainfall. To reveal detailed spatial distribution of rainfall features in the four study regions during early-morning, the regions with the most obvious signals were selected and every region is divided to 4 sub-regions with considering the combination of mountains extending direction and the terrain height variation from the lower to the higher elevation. The mountains stretch from southwest to northeast in the NW, simultaneously, the mountainous height gradually increases. The altitude of mountains gradually increases form west to east in the SW. The mountains present southnorth-oriented extending with the terrain height gradually increasing in the SE. The altitude of mountains increases form south to north in the NE.

The spatial patterns of rainfall amount (Fig. 7) during early-morning are considerably similar to that of the warm season rainfall amount (Fig. 2). It is notable that the rainfall amount approximately increases as the terrain height increases in four study regions. In every study region, the relatively small value stations of rainfall amount are located in the first sub-region, and the large stations mainly concentrate in the fourth sub-region. In the NW and the SE, the rainfall amount gradually increases along the direction of mountains, especially in the south side of mountains. In the SW and the NE, the rainfall amount gradually increases from the foot to the top of mountains.

For more detailed investigation of the rainfall variations in the four study regions, Fig. 8 presents variations of the rainfall amount for four sub-regions in every study region at the different elevation. Along the mountains from southwest to northeast, the average elevations of the sub-regions stations increase from $346.1 \mathrm{~m}$ to $536.4 \mathrm{~m}$ in the NW (Fig. 8a). Meanwhile, the mean, median, upper quartile and maximum values of rainfall amount in 4 sub-regions also increase, ranging from $0.315,0.313,329$, and $0.363 \mathrm{~mm} \mathrm{~h}^{-1}$, in the first sub-region to $0.378,0.380,0.397$, and $0.470 \mathrm{~mm} \mathrm{~h}^{-1}$, respectively, in the fourth sub-region. In the SW (Fig. 8b), the average terrain heights gradually increase from $405.5 \mathrm{~m}$ to $666.5 \mathrm{~m}$, and the mean $\left(0.344 \mathrm{~mm} \mathrm{~h}^{-1}\right)$ and median $\left(0.345 \mathrm{~mm} \mathrm{~h}^{-1}\right)$ values in westernmost sub-region increase 0.383 and $0.376 \mathrm{~mm} \mathrm{~h}^{-1}$ in easternmost sub-region. In addition, we should notice that the mean and median values in the second sub-region are slightly smaller than those in the first sub-region, which are influenced by the stations in the low altitude terrain, but the slightly different variation does not affect the overall change with terrain height. The mean, median, and minimum values of rainfall amount in the southernmost region are $0.316,0.319$, and $0.266 \mathrm{~mm} \mathrm{~h}^{-1}$, respectively, whereas those in the northernmost region reach $0.427,0.436$, and $0.378 \mathrm{~mm} \mathrm{~h}^{-1}$, respectively in the SE. For the rainfall amount, practically all statistics increase along the mountain extending in the SE (Fig. 8c). Simultaneously, the average elevations of the sub-regions stations gradually increase from $431.7 \mathrm{~m}$ to $719.9 \mathrm{~m}$. Figure $6 \mathrm{~d}$ also 
presents the obvious feature that is the rainfall amount consistent variations with elevation increasing. The mean rainfall amount in the southernmost region is only $0.247 \mathrm{~mm} \mathrm{~h}^{-1}$ whereas that in the northernmost region reaches $0.398 \mathrm{~mm} \mathrm{~h}^{-1}$.

Boxplot of stations rainfall amount in four study regions all show the characteristics of consistent variations with the terrain heights increasing. The results explain elevation play an important role that affects the local distributions in rainfall.

Similar to rainfall amount, the rainfall frequency also shows different spatial variations in four study regions (Fig. 9), and there are also increasing features along the terrain height increasing of the mountains. The small value stations of rainfall amount are located in the first sub-region, and the large stations are concentrated in the fourth sub-region. The rainfall frequency has a clearer increase along the extending direction of mountains in the NW and the SE, and those also have a similar increasing trend with the terrain height gradually increasing form the low inlands to the high hills of mountains in the SW and the NE. The values in the top are also bigger than those in the foot at the same longitudes or latitudes.

The detailed rainfall frequency correspondingly changes with the topographic elevation, as shown in Fig. 10. In the southwest-northeast direction in the NW (Fig. 10a), the rainfall exhibits consistent variations with elevation, in terms of rainfall amount and frequency. The mean rainfall frequency in the first subregion is 0.174 whereas that in the fourth sub-region reaches 0.191 . In the SW (Fig. 10b), from west to east along the mountains, the mean terrain heights are $405.5,418.9$, and $453.9 \mathrm{~m}$, respectively, which slightly increase within $100 \mathrm{~m}$, but the elevations increase to $666.5 \mathrm{~m}$ with over $200 \mathrm{~m}$ higher than those in 1-3 sub-regions. Due to the terrain heights variation, the mean and median stay relatively consistent in 1-3 sub-regions, but that obviously increases in the fourth sub-region. The mean (0.169) and median (0.173) values in southernmost sub region increase 0.210 and 0.210 compared with northernmost sub region in the SE (Fig. 10c). Meanwhile, it should be noted that the mean and median values are slightly smaller in the second sub-region than those in the first sub-region, but the slightly different variation also does not affect the overall variation tendency of rainfall frequency with terrain height. There is an increase in the rainfall frequency concurrent with the increasing elevations over 1-4 sub-regions in the $\mathrm{NE}$. The mean, median, upper quartile and maximum values increase, ranging from $0.134,0.135,0.139$, and 0.151 , respectively, in the first sub-region to $0.183,0.178,0.193$, and 0.260 , respectively, in the fourth sub-region.

From the above discussion of the spatial variations of the rainfall over four focus regions, the results show that the rainfall amount and frequency at higher elevations are larger than those at lower elevations, and the rainfall amount and frequency significantly increases as the terrain height sharply increase, which indicates mountains terrain exhibits a remarkable enhancement effect on precipitation in four study regions.

\subsection{The diurnal variation of rainfall events in different area}


To explore the relationships between rainfall occurring time and the duration hour of the rainfall events, the rainfall amount and frequency decomposed by duration and diurnal phase for four study regions are analyzed, which are normalized by the daily mean of each duration time. The rainfall occurring overnight (2000-0800 LST) constitutes the total rainfall in the four study regions. In the NW, rainfall with duration of less than $6 \mathrm{~h}$ reaches its peak at roughly 0400 LST in the early-morning. Rainfall events lasting more than $6 \mathrm{~h}$ tend to peak between 0200 and 0400 LST. However, it can be seen clearly that the amount and frequency of rainfall events that last longer than $6 \mathrm{~h}$ is higher than that of lasting less than $6 \mathrm{~h}$, and this kind of rainfall occurs mostly in the early-morning. In the SW, rainfall with duration less than $6 \mathrm{~h}$ reaches its peak at roughly 2000 LST in the afternoon, and a less pronounced second peak is observed at 0400 LST in the early-morning. Rainfall events lasting more than $6 \mathrm{~h}$ tend to peak between 0200 and $0400 \mathrm{LST}$. Similar results are found in the SE, though rainfall with lasting less than $6 \mathrm{~h}$ reaches its peak at roughly $0000 \mathrm{LST}$ in the midnight. In the NE, rainfall events lasting less and more than $6 \mathrm{~h}$ mainly occur in the nighttime.

From the above analysis, there are large value zones $(\geq 0)$ that start from short-duration precipitation (16 hour), and extend to long-duration rainfall ( $>6$ hours) from the afternoon period to the early-morning period. In other words, short-duration rainfall events tend to start between the afternoon and the night while long-duration rainfall events tend to start in the night. Nocturnal rainfall events tend to begin simultaneously while long-duration rainfall ends later, showing that long-duration rainfall events make a larger contribution to total rainfall amount. The duration is closely related to the physical mechanisms of precipitation.

Yu et al. (2007a) revealed that the diurnal cycle of long-duration precipitation exhibits an early-morning maximum while short-duration precipitation an afternoon to evening maximum. The late-afternoon maximum can be explained by surface solar heating, which results in maximum low-level atmospheric instability and thus moist convection in the afternoon. The nocturnal maximum may result from the diurnal variation of local circulation forced by the complex terrain.

Similar to Fig. 5, the proportions of two main periods for rainfall events with different durations are shown for the four regions (Fig. 12). When the duration is between 1 and $3 \mathrm{~h}$, the rainfall frequency proportion $(25.6 \%)$ in the early-morning period is greater than that $(17.1 \%)$ in the late-afternoon period in the NW, but the rainfall amount proportion (4.5\%) in the early-morning is slightly smaller than that (5.8\%) in the late-afternoon. The rainfall frequency proportion of durations of $4-6 \mathrm{~h}(10.6 \%), 7-9 \mathrm{~h}(5.2 \%), 10-12$ $\mathrm{h}(2.6 \%)$, and more than or equal to $13 \mathrm{~h}(3.1 \%)$ in the early-morning period are roughly triple as much as that in the early-morning period, which are $3.2 \%, 1.0 \%, 0.6 \%$, and $1.9 \%$, respectively. The rainfall amount proportion of durations of $4-6 \mathrm{~h}(9.9 \%), 7-9 \mathrm{~h}(9.4 \%), 10-12 \mathrm{~h}(7.2 \%)$, and more than or equal to 13 $\mathrm{h}(16.6 \%)$ in the early-morning period are roughly twice as much as that in the early-morning period, which are $4.3 \%, 1.4 \%, 1.2 \%$, and $8.9 \%$, respectively.

Similar results are shown in the following three regions. For proportions of rainfall events, more than $35 \%$ short-duration rainfall (1-6h) events happen during the early-morning period. When the duration is above 
$7 \mathrm{~h}$, the frequency proportion is slightly greater than $10 \%$, accounting for $33.2 \%$ of the total rainfall.

Although the diurnal large value zones of rainfall events in the four regions appear in the early-morning, the detailed diurnal rainfall cycles are different. We will further analyze the peak time characteristics of rainfall events with different duration in the following.

The peak of long persistent precipitation is usually in the morning, which accounts for more than $60 \%$ of precipitation in central and eastern China, while short persistent precipitation mainly appears in the afternoon (Yu et al.,2007a). The occurrence of the rainfall maximum is important for rainfall events (Yu et al.,2013). To quantitatively assess the relationship between the gauge elevation and the early-morning maximum rainfall, Fig. 13 shows the relationships of the gauge elevation and the proportion of rainfall maximum frequency during the early-morning period to the total daily rainfall frequency trend magnitude. There are obviously negative correlations between the proportion trend magnitudes and the elevation in four regions. The linear correlation coefficients $(R)$ are $-0.932,-0.878,-0.914$, and -0.803 , respectively, which pass the significance test at the $99 \%$ confidence level. It means that the proportions of earlymorning rainfall maximum frequency to the total rainfall over the higher elevations are smaller than that of the lower elevations. This suggests that the altitude effect of the early-morning rainfall maximum frequency is significant. The early-morning rainfall maximum trend obviously diminishes with elevation, which indicates that the high mountainous areas experience more other raining periods than that at lower elevations.

\section{Conclusions And Discussion}

Based on the hourly rain-gauge data of high density stations in Chongqing during the warm season (May to September) from 2009 to 2016, the overall features and regional differences in the diurnal variations of rainfall affected by complex terrain are identified, and the detailed influences of the gauge elevations on the diurnal variations of rainfall are also investigated. The main conclusions can be summarized as follows.

(1) The spatial features of rainfall amount, frequency, and intensity have obvious regional characteristics. The terrain has a significant impact on the spatial distribution characteristics of precipitation. Mountainous terrain areas obviously enhance on rainfall. The stations with large rainfall amount, frequency and intensity values are located in the higher complex mountainous terrain areas, especially in four study regions we select. The early-morning peaks have played dominant role for the rainfall frequency and amount, which account for $81.9 \%$ and $88.1 \%$ of all stations, respectively, but the patterns of the rainfall intensity are apparently heterogeneous.

(2) The diurnal characteristics of rainfall amount, frequency, and intensity have obvious regional characteristics, and the maximum peak time periods are relatively consistent in reaching their maxima in the early-morning. The rainfall amount has dual structure with a dominant early-morning peak at approximately 0700 LST (23 UTC), and a weaker secondary late-afternoon peak at approximately 1600 
LST (08 UTC). There is a single peak diurnal characteristic of the rainfall frequency in the SW, NW, and $\mathrm{SE}$, but for dual peak in the NE.

(3) The gauge elevation has a significant impact on the diurnal variations of the early-morning rainfall. As elevation decreases, the proportion of the rainfall amount (frequency) that occurs during early-morning periods increase in four study regions. In other words, the early-morning peak dominates in low elevations areas, and the high mountainous areas experience more other raining periods than that at lower elevations. The same findings are shown regarding the proportions of early-morning rainfall maximum frequency to the total rainfall events.

(4) The detailed characteristics of four study regions show that the rainfall amount and frequency at the higher elevations are larger than those at the lower elevations, and the rainfall amount and frequency significantly increase, especially in the direction that terrain height sharply increases along mountains extending.

(5) Different duration hours of rainfall events rainfall have distinct diurnal variation and diurnal phase features. Short-duration rainfall tends to start between the afternoon and the night while long-duration rainfall tends to start in the night. Nocturnal rainfall events tend to begin simultaneously while longduration rainfall ends later, showing that long-duration rainfall events make a larger contribution to total rainfall amount.

In this study, our results indicate that the features of diurnal variation in Chongqing are significantly affected by the topography, and demonstrate the dominance of early-morning rainfall in determining the distinct diurnal features of warm season rainfall. Prevailing nocturnal precipitation over the eastern Tibetan Plateau and its eastern periphery was discussed previously (Bai et al.,2008; Chen et al.,2009; Huang et al.,2010;Guo et al.,2016), but the underlying mechanisms remain unclear. Jin et al. (2013) suggested that the early night precipitation peak over the western SCB is largely caused by strong ascending motion over the TP and its eastern lee side, while multiple coexisting factors contribute to the late night peak of precipitation over the central and eastern SCB. The mountain-plain solenoid circulation, driven by heterogeneous diabatic heating associated with topographic forcing, contribute to the nocturnal precipitation over the SCB(Zhang et al.,2014b;Qian et al.,2015). In the early evening, anomalous easterly flow moves toward the TP and causes low-level convergence over the western SCB, resulting in nocturnal precipitation over the SCB(Sun and Zhang, 2012; Yuan et al.,2014;Chen et al.,2017;Zhang F.et al.,2019). Prominent diurnal inertial oscillations of south-southwesterly low-level jet into the southeast side of the SCB play an important role in modulating the diurnal variation of precipitation over the SCB (Zhang Y et al.,2019). Qian et al. (2015) found that the precipitation over the SCB propagates northeastward in the early night and decays. As mentioned before, the west Chongqing goes into the SCB, in which the diurnal variation of rainfall is the same as in the SCB, while the eastern and middle Chongqing are located in the mountainous area surrounding the basin and gradually rises eastward with high terrain spreading on Wu Mountain (WM). Chen et al. (2019) investigating the interval of precipitation associated with the diurnal distribution of lightning reveals that the enhancement of precipitation in the mountainous area. However, 
the present study is limited by the use of only station observations, due to the limited data length, heterogeneous spatial distribution of the stations, and scarce records of rainfall in mountainous area, which cannot fully reveal the interactions between the local topography and mesoscale processes in the generation of heavy rainfall.

It is noteworthy that there are obvious regional characteristics in the diurnal variations of rainfall. The study could be helpful in further understanding the precipitation characteristics in Chongqing and in researches on precipitation over complex terrain in the southwest China. The diurnal rainfall cycles of rainfall amount and intensity are the same in the SW and NW, and they are generally consistent with the SE and NE. The SW and NW are located in the west Chongqing, and go deep into the SCB at low elevation. The east Chongqing gradually rises with high height terrain, in which the SE and NE are located. The elevation is an obvious different topography factor. The rainfall amount and frequency significantly increase as the terrain height sharply increases, especially in the NE, and the direction of orographic slope is north-south orientation where the windward slope zone with the terrain interacts with the south wind. The detailed rainfall characteristic is also different in the sub-regions over four study regions. These differences in the sub-regions imply that apart from the elevation, some other topography related factors, such as orographic slope and orientation, should also be considered when investigating the influence of topography on the diurnal variations of rainfall. Due to the few stations located in sparsely mountainous areas, it is difficult to obtain detailed circulation characteristics and to truly understand physical processes behind these differences in complex terrain area. Therefore, further studies are needed to validate the results using other high high-resolution data, including the highresolution satellite data, and high-resolution numerical experiments should be designed and carried out in future works.

\section{Declarations}

Funding information

This research was supported by the National Key R\&D Program of China (Grants 2018YFC1507504 and 2017YFC1502003), Chongqing Natural Science Foundation of China (cstc2015jcyJA00039), Chongqing Technology Innovation and Application Demonstration Project (cstc2018jscx-msybX0162)and the Business Technology Research Project of Chongqing Meteorological Bureau (YWJSGG-202120). We are thankful National Meteorological Information Center of the China Meteorological Administration for providing data.

Author's contribution

Li Qiang analyzed the data, made the figures and wrote the paper. Zheng Yongguang and Zhou Guobing gave scientific advice and helped improve the paper. Zhu Yan and Liu Chao revised the language and characters. All the authors contributed to the discussion and final version of the paper. All authors read and approved the final manuscript. 
Availability of data and material

All data used during the study appear in the submitted supporting data.

Code availability

Code generated or used during the study are available from the corresponding author on reasonable request.

Declaration of Competing Interest

The authors declare that they have no competing interests.

Ethics approval

Not applicable.

Consent to participate

Not applicable.

Consent for publication

Not applicable.

\section{References}

1. Bai AJ, Liu CH, Liu XD (2008) Diurnal variation of summer rainfall over the Tibetan Plateau and its neighboring regions revealed by TRMM multi-satellite precipitation analysis. Chinese J Geophys 51:518-529. doi:10.1002/cjg2.1242

2. Bao XH, Zhang FQ, Sun JH (2011) Diurnal variations of warm-season precipitation east of the Tibetan Plateau over China. Mon Wea Rev 139:2790-2810. doi:10.1007/s00382-017-4042-x

3. Barros, A. P., and Lang, T. J., 2003. Monitoring the monsoon in the Himalayas: Observations in central Nepal, June 2001. Mon. Wea. Rev., 131, 1408-1427. doi:10.1175/15200493(2003)131<1408:MTMITH>2.0.C0;2

4. Basist, A., Bell, G.D., Meentemeyer, V., 1994. Statistical relationships between topography and precipitation patterns. J. Clim., 7, 1305-1315. doi:10.1175/15200442(1994)007<1305:SRBTAP>2.0.CO;2

5. Burbank DW, Blythe AE, Putkonen J et al (2003) Decoupling of erosion and precipitation in the Himalayas. Nature 426(6967):652-655. doi:10.1038/nature02187

6. Chen CS, Lin YL, Zeng HT et al (2013) Orographic effects on heavy rainfall events over northeastern Taiwan during the northeasterly monsoon season. Atmos Res 122:310-335. doi:10.1016/j.atmosres.2012.10.008 
7. Chen H, Li J, Yu R (2018) Warm season nocturnal rainfall over the eastern periphery of the Tibetan Plateau and its relationship with rainfall events in adjacent regions. Int J Climatol 38:4786-4801. doi:10.1002/joc.5696

8. Chen GX, Sha WM, Iwasaki T, Wen ZP (2017) Diurnal cycle of a heavy rainfall corridor over East Asia. Mon Wea Rev 145:3365-3386. doi:10.1175/MWRD-16-0423.1

9. Chen GX, Sha W, Iwasaki T,2009. Diurnal variation of precipitation over southeastern China: spatial distribution and its seasonality. J Geophys Res Atmos,114(D13). doi:10.1029/2008jd011103

10. Chen S, Yan Y, Liu G et al (2019) Spatiotemporal characteristics of precipitation diurnal variations in Chongqing with complex terrain. Theor Appl Climatol 137:1217-1231. doi:10.1007/s00704-0182662-7

11. Chen GX, Sha WM, Iwasaki et al (2017) Diurnal cycle of a heavy rainfall corridor over East Asia. Mon Wea Rev 145:3365-3386. doi:10.1175/MWR-D-16-0423.1

12. Chen $Y$, Wang $X$, Huang $L$ et al. 2021.Spatial and temporal characteristics of abrupt heavy rainfall events over Southwest China during 1981-2017. Int J Climatol. 41, 3286-3299. doi:10.1002/joc.7019

13. Chongqing Bureau of Geology and Minerals Exploration (CBGM) (2002) Structure outline map of Chongqing and instruction. Geological Publishing House, (in Chinese)

14. Colle, B. A., 2004. Sensitivity of orographic precipitation to changing ambient conditions and terrain geometries: An idealized modeling perspective. J. Atmos. Sci., 61, 588-606. doi:10.1175/15200469(2004)061<0588:SOOPTC>2.0.C0;2

15. Couto FT, Ducrocq V, Salgado R et al (2016) Numerical simulations of significant orographic precipitation in Madeira island. Atmos Res 169:102-112. doi:10.1016/j.atmosres.2015.10.002

16. Cuo L, Zhang Y (2017) Spatial patterns of wet season precipitation vertical gradients on the Tibetan Plateau and the surroundings. Sci Rep 7(1):5057. doi:10.1038/s41598-017-05345-6

17. Dai A, Giorgi F, Trenberth KE (1999) Observed and model simulated diurnal cycles of precipitation over the contiguous united states. J Geophys Res 104(D6):6377-6402. doi:10.1029/98jd02720

18. DeHart JC, Houze RA (2017) Orographic modification of precipitation processes in Hurricane Karl (2010). Mon Wea Rev 145:4171-4186. doi:10.1175/MWR-D-17-0014.1

19. Deshpande NR, Kulkarni A, Krishna Kumar K (2012) Characteristic features of hourly rainfall in India. Int J Climatol 32(11):1730-1744. doi:10.1002/joc.2375

20. Fu P, Zhu K, Zhao, Kun,et al (2019) Role of the Nocturnal Low-level Jet in the Formation of the Morning Precipitation Peak over the Dabie Mountains. Adv Atmos Sci 36(1):15-28. doi:10.1007/s00376-018-8095-5

21. Gan YT, Li NN, Li J (2019) Differences in the rainfall characteristics between Mount Tai and its surrounding areas. J Meteor Res 33(5):976-988. doi:10.1007/s13351-019-9006-0

22. Giorgi, F., Hurrell, J.W., Marinucci, M.R., et al., 1997. Elevation dependency of the surface climate change signal: a model study. J. Clim., 10 (2), 288-296. doi: 10.1175/1520- 
0442(1997)010<0288:edotsc $>2.0 . c 0 ; 2$

23. Goovaerts $P$ (2000) Geostatistical approaches for incorporating elevation into the spatial interpolation of rainfall. J Hydrol 228:113-129. doi:10.1016/S0022-1694(00)00144-X

24. Guo JP, Zhai PM, Wu L et al (2014) Diurnal variation and the influential factors of precipitation from surface and satellite measurements in Tibet. Int J Climatol 34:2940-2956. doi:10.1002/joc.3886

25. Guo X, Wang L, Tian L (2016) Spatio-temporal variability of vertical gradients of major meteorological observations around the Tibetan Plateau. Int J Climatol 36(4):1901-1916. doi:10.1002/joc.4468

26. Hitchens NM, Brooks HE, Schumacher RS (2013) Spatial and temporal characteristics of heavy hourly rainfall in the United States. Mon Wea Rev 141(12):4564-4575. doi:10.1175/MWR-D-1200297.1

27. Houze RA (2012) Orographic effects on precipitating clouds. Rev Geophys 50:RG1001. doi:10.1029/2011RG000365

28. Huang HL, Wang CC, Chen GTJ et al (2010) The role of diurnal solenoidal circulation on propagating rainfall episodes near the eastern Tibetan Plateau. Mon Wea Rev 138:2975-2989. doi:10.1175/2010MWR3225.1

29. Iwasaki H (2012) Recent positive trend in heavy rainfall in eastern Japan and its relation with variations in atmospheric moisture. Int J Climatol 32(3):364-374. doi:10.1002/joc.2269

30. Iwasaki H (2015) Increasing trends in heavy rain during the warm season in eastern Japan and its relation to moisture variation and topographic convergence. Int J Climatol 35(8):2154-2163. doi:10.1002/joc. 4115

31. Jiang QF, Smith RB (2003) Cloud timescales and orographic precipitation. J Atmos Sci 60:15431559. doi: $10.1175 / 2995.1$

32. Jin X, Wu TW, Li L (2013) The quasi-stationary feature of nocturnal precipitation in the Sichuan Basin and the role of the Tibetan Plateau. Climate Dyn 41(3-4):977-994. doi:10.1007/s00382-012$1521-y$

33. Johansson B, Chen D (2003) The influence of wind and topography on precipitation distribution in Sweden: statistical analysis and modelling. J Climatol 23:1523-1535. doi:10.1002/joc.951

34. Kang Y, Peng X, Wang S et al (2019) Observational analyses of topographic effects on convective systems in an extreme rainfall event in Northern China. Atmos Res 229:127-144. doi:10.1016/j.atmosres.2019.05.024

35. Kirshbaum DJ (2011) Cloud-resolving simulations of deep convection over a heated mountain. J Atmos Sci 68:361-378. doi:10.1175/2010JAS3642.1

36. Kirshbaum D, Adler $\mathrm{B}$, Kalthoff $\mathrm{N}$ et al., 2018. Moist orographic convection: Physical mechanisms and links to surface-exchange processes. Atmosphere.9(3), 80. doi:10.3390/atmos9030080

37. Leahy PG, Kiely G (2011) Short duration rainfall extremes in Ireland: influence of climatic variability. Water Resour Manage 25(3):987-1003. doi:10.1007/s11269-010-9737-2 
38. Lee KO, Shimizu S, Maki M,et al (2010) Enhancement mechanism of the 30 June 2006 precipitation system observed over the northwestern slope of Mt. Halla, Jeju Island, Korea. Atmos Res 97(3):0358. doi:10.1016/j.atmosres.2010.04.008

39. Li J (2017a) Hourly station-based precipitation characteristics over the Tibetan Plateau. Int J Climatol 38:1560-1578. doi:10.1002/joc.5281

40. Li J, Chen TR, Li NN (2017b) Diurnal variation of summer precipitation across the central Tian Shan Mountains. JAppl Meteor Climatol 56:1537-1550. doi:10.1175/JAMC-D-16-0265.1

41. Li LL, Li J, Chen H, Yu R (2019) Diurnal variations of summer precipitation over the Qilian mountains in Northwest China. J Meteorol Res 33:18-30. doi:10.1007/s13351-019-8103-4

42. Li LL, Li J, Yu RC (2020) Characteristics of summer regional rainfall events over lli River Valley in Northwest China. Atmos. Res.,243(2020),104996.doi:10.1016/j.atmosres.2020.104996

43. Li J, Li Y, Zhao T et al., 2020. Northeastward propagation of nocturnal precipitation over the Sichuan Basin. Int J Climatol, 1-17. doi:10.1002/joc.6886

44. Liang XZ, Li L, Dai A, Kunkel KE (2004) Regional climate model simulation of summer precipitation diurnal cycle over the United States. Geophysical Research Letters 31(24):L24208. doi:10.1029/2004GL021054

45. Liao F, Hong YC, Zheng GG (2007) Review of orographic influences on surface precipitation(in Chinese). Meteor Sci Technol 35:309-316. doi:10.19517/j.1671-6345.2007.03.001

46. Liu XD, Bai AJ, Liu CH (2009) Diurnal variations of summertime precipitation over the Tibetan Plateau in relation to orographically-induced regional circulations. Environmental Research Letters 4(4):940-941. doi:10.1088/1748-9326/4/4/045203

47. Liu JF, Chen RS, Qin WW,et al (2011) Study on the vertical distribution of precipitation in mountainous regions using TRMM data(in Chinese). Adv Water Sci 22(4):447-454. doi:10.14042/j.cnki.32.1309.2011.04.001

48. Luo Y, Wu M, Ren F,et al (2016) Synoptic situations of extreme hourly precipitation over China. J Climate 29(24):8703-8719. doi:10.1175/JCLI-D-16-0057.1

49. Peng NZ, Fu BP, Yu Q et al (1995) Some climatically statistical features of storm with orography in China (in Chinese). Scientia MeteorSinica 15(3):288-292

50. Purnell DJ, Kirshbaum DJ (2018) Synoptic control over orographic precipitation distributions during the Olympics Mountains Experiment (OLYMPEX). Mon Wea Rev 146:1023-1044. doi:10.1175/mwrd-17-0267.1

51. Qian T, Zhao P, Zhang F et al (2015) Rainy-season precipitation over the Sichuan Basin and adjacent regions in southwestern China. Mon Wea Rev 143(1):383-394. doi:10.1175/MWR-D-13-00158.1

52. Roe GH (2005) Orographic precipitation. Annu Rev Earth Planet Sci 33:645-671. doi:10.1146/annurev.earth.33.092203.122541

53. Rotunno R, and Houze R. A (2007) Lessons on orographic precipitation from the Mesoscale Alpine Programme. Quart JRoy Meteor Soc 133:811-830. doi:10.1002/qj.67 
54. Sarmadi F, Huang Y, Thompson $G$ et al (2019) Simulations of orographic precipitation in the Snowy Mountains of Southeastern Australia. Atmos Res 219:183-199. doi:10.1016/j.atmosres.2019.01.002

55. Silverman NL, Maneta MP, Chen SH et al (2013) Dynamically downscaled winter precipitation over complex terrain of the Central Rockies of Western Montana, USA. Water Resour Res 49:458-470. doi:10.1029/2012wr012874

56. Smith RB (1979) The Influence of Mountains on the Atmosphere. Adv Geophys 21:87-230. doi:10.1016/S0065-2687(08)60262-9

57. Smith, R. B., and Barstad I., 2004. A linear theory of orographic precipitation. J. Atmos. Sci., 61, 1377-1391, doi: 10.1175/1520-0469(2004)061<1377:altoop>2.0.co;2

58. Sokol Z, Bližňák V (2009) Areal distribution and precipitation-altitude relationship of heavy short-term precipitation in the Czech Republic in the warm part of the year. Atmos Res 94:652-662. doi:10.1016/j.atmosres.2009.03.001

59. Sun JH, Zhang FQ (2012) Impacts of mountain-plains solenoid on diurnal variations of rainfalls along the Mei-Yu front over the East China Plains. Mon Wea Rev 140(2):379-397. doi:10.1175/MWR-D-11-00041.1

60. Stevenson SN, Schumacher RS (2014) A 10-year survey of extreme rainfall events in the central and eastern United States using gridded multisensor precipitation analyses. Mon Wea Rev 142(9):31473162. doi:10.1175/MWR-D-13-00345.1

61. Tao SY (1980) Heavy Rain in China (in Chinese). Science Press, Beijing, 225 pp

62. Wang D, Miao JF, Tan ZM (2013) Impacts of topography and land cover change on thunderstorm over the Huangshan (Yellow Mountain) area of China. Nat Hazards 67:675-699. doi:10.1007/s11069-013-0595-0

63. Wang QW, Xue M, Tan ZM (2016) Convective initiation by topographically induced convergence forcing over the Dabie Mountains on 24 June 2010. Adv Atmos Sci 33:1120-1136. doi:10.1007/s00376-016-6024-z

64. Wang Z, Yang S, Lau NC et al (2018) Teleconnection between Summer NAO and East China Rainfall Variations: A Bridge Effect of the Tibetan Plateau. J Clim. doi:10.1175/jcli-d-17-0413.1

65. Weisse, A. K., and Bois P., 2001. Topographic effects on statistical characteristics of heavy rainfall and mapping in the French Alps. J. Appl. Meteor. 40, 720-740. doi:10.1175/15200450(2001)040<0720:TEOSCO>2.0.C0;2

66. White AB, Paul JN (2015) The Impacts of California's San Francisco Bay Area Gap on Precipitation

67. Observed in the Sierra Nevada during HMT and CalWater. J. Hydro. meteorol., 16, 1048-1069. doi:10.1175/JHM-D-14-0160.1

68. Xu WX, Zipser EJ (2011) Diurnal variations of precipitation, deep convection, and lightning over and east of the eastern Tibetan Plateau. J Climate 24(2):448-465. doi:10.1175/2010JCLI3719.1

69. Xue M, Luo X, Zhu KF, Sun ZQ, Fei JF (2018) The controlling role of boundary layer inertial oscillations in Meiyu frontal precipitation and its diurnal cycles over China. Journal of Geophysical 
Research:Atmospheres 123(10):5090-5115. doi:10.1029/2018jd028368

70. Yu H, Wang L, Yang R et al (2018) Temporal and spatial variation of precipitation in the Hengduan Mountains region in China and its relationship with elevation and latitude. Atmos Res 213:1-16. doi:10.1016/j.atmosres.2018.05.025

71. Yu RC, Xu YP, Zhou TJ et al., 2007a. Relation between rainfall duration and diurnal variation in the warm season precipitation over central eastern China. Geophys Res Lett, 34,L13703, doi:10.1029/2007GL030315

72. Yu RC, Zhou TJ, Xiong AY et al (2007b) Diurnal variationsof summer precipitation over contiguous China. Geophys Res Lett 34:L01704. doi:10.1029/2006GL028129

73. Yu RC, Li J, Chen HM et al (2014) Progress in studies of the precipitation diurnal variation over contiguous China. J MeteorRes 28:877-902. doi:10.1007/s13351-014-3272-7

74. Yu RC, Yuan W, Li J (2013) The asymmetry of rainfall process. China Sci Bull 58:1850-1856. doi:10.1007/s11434-012-5653-6

75. Yuan WH, Yu RC, Fu YF (2014) Study of different diurnal variations of summer long-duration rainfall between the southern and northern parts of the Huai River. Chinese Journal of Geophysics 57(2):145-153. doi:10.1002/cjg2.20092

76. Zhang F, Li G, Yue J (2019) The moisture sources and transport processes for a sudden rainstorm associated with double low-level jets in the northeast Sichuan Basin of China. Atmosphere,10(3), 160. doi:10.3390/atmos 10030160

77. Zhang YC, Zhang FQ, Sun JH (2014a) Comparison of the diurnal variations of warm-season precipitation for East Asia vs. North America downstream of the Tibetan Plateau vs. the Rocky Mountains. Atmos Chem Phys 14:10741-10759. doi:10.5194/acp-14-10741-2014

78. Zhang YC, Sun JH, Fu SM (2014b) Impacts of diurnal variation of mountain-plain solenoid circulations on precipitation and vortices east of the Tibetan Plateau during the Meiyu season. Adv Atmos Sci 31(1):139-153. doi:10.1007/s00703-016-0484-7

79. Zheng Y, Xue M, Li B et al (2016) Spatial characteristics of extreme rainfall over China with hourly through 24-hour accumulation periods based on national-level hourly rain gauge data. Adv Atmos Sci 33(11):1218-1232. doi:10.1007/s00376-016-6128-5

80. Zhang Y, Xue M, Zhu K,et al (2019) What is the main cause of diurnal variation and nocturnal peak of summer precipitation in Sichuan Basin,China? The key role of boundary layer low-level jet inertial oscillations. Journal of Geophysical Research:Atmospheres 124:2643-2664. doi:10.1029/2018JD029834

81. Zhou T, Yu RC, Chen H et al (2008) Summer precipitation frequency, intensity, and diurnal cycle over China: A comparison of satellite data with rain gauge observations. J Climate 21(16):3997-4010. doi:10.1175/2008JCLI2028SI

\section{Figures}




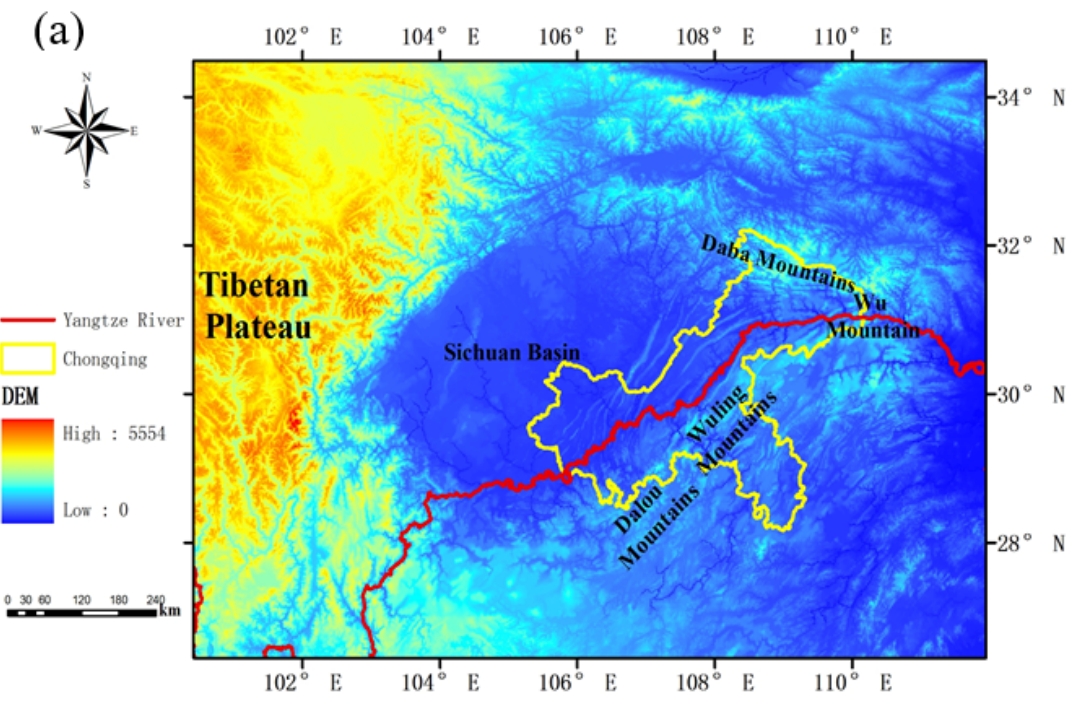

(b)

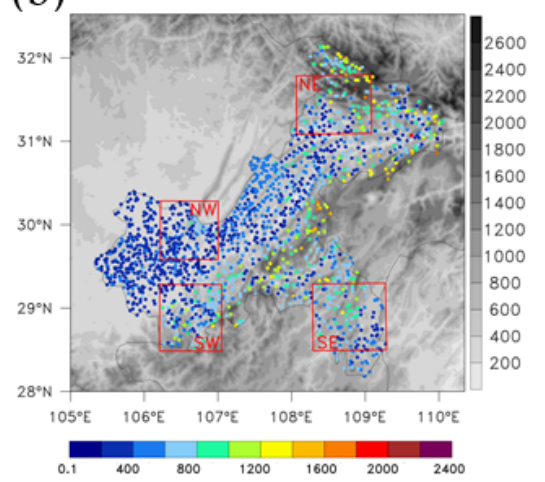

(c)

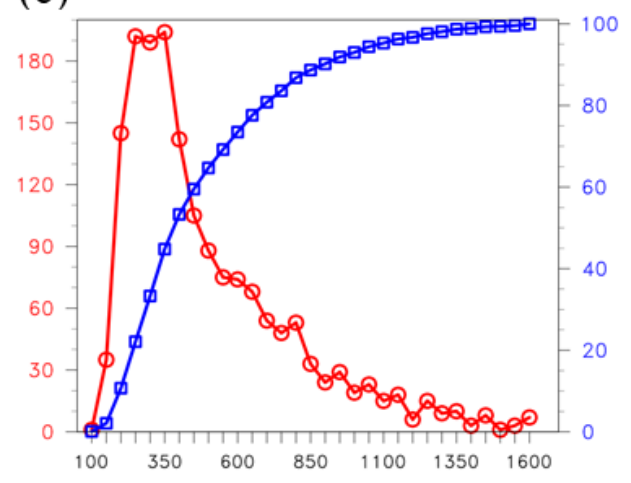

(d)

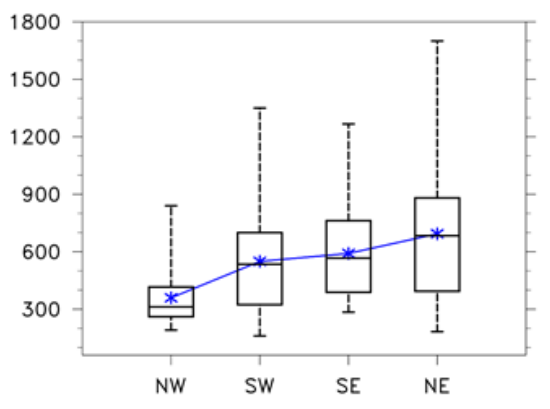

Figure 1

(a) The geographical location of Chongqing (yellow lines). The red line shows the Yangtze River. The distributions of 1868 rain-gauge stations (b: colored dots). The red boxes represent four study areas. Gray shadings indicate topography (unit: $\mathrm{m}$ ). The numbers of station (c: left $y$-axis) as a function of terrain height (c: $x$-axis, the $1600 \mathrm{~m}$ scale of $\mathrm{x}$-axis indicates the numbers of stations above $1600 \mathrm{~m}$ ) (c) and the proportions of different terrain height (c: right y-axis). Boxplot of stations terrain height of four study regions (d); box shows lower and upper quartiles. Black lines inside boxes represent medians. Blue dots are for average terrain elevation. Minimum and maximum values are shown by whiskers. 

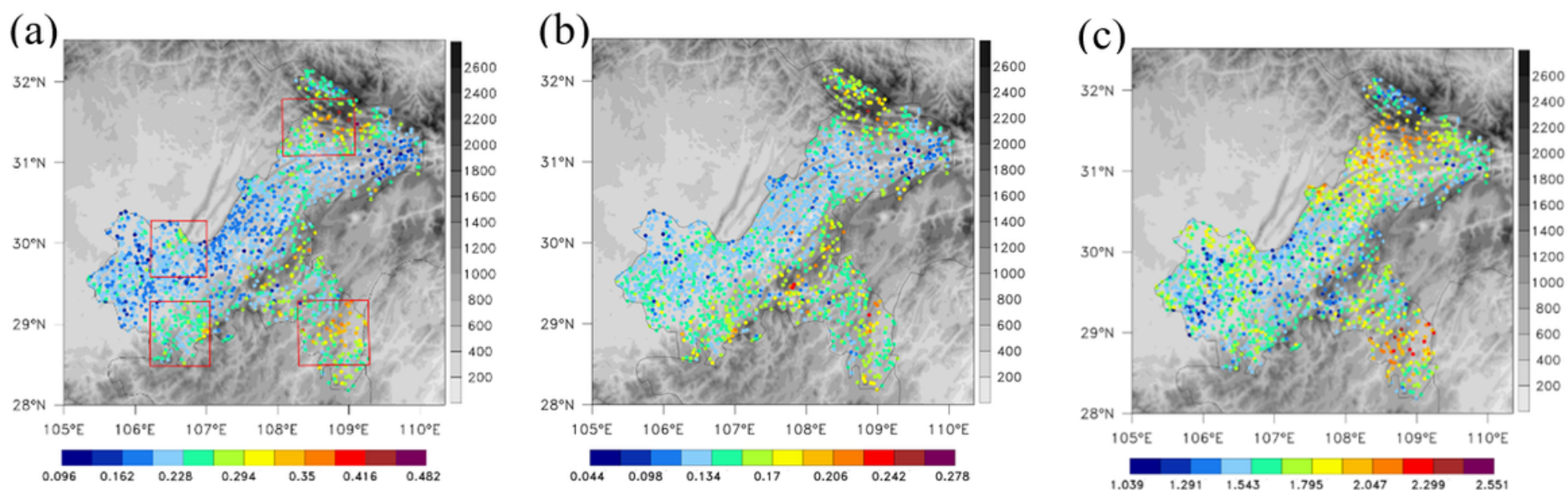

Figure 2

Different in warm season rainfall (a) amount (colored dots; mm h-1), (b)frequency (colored dots), and (c) intensity (colored dots; mm h-1) over 2016-2020. Grey shadings indicate the terrain elevation.
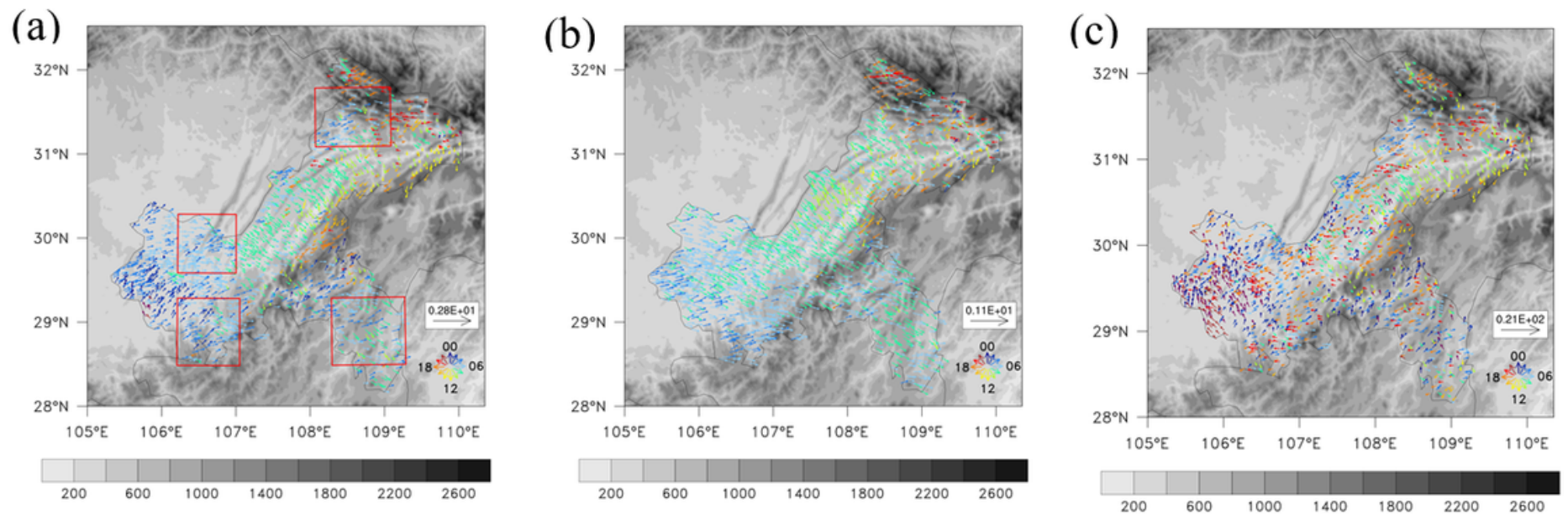

\section{Figure 3}

Diurnal peaks of warm season rainfall (a) amount, (b) frequency, and (c) intensity over 2016-2020.

(a)

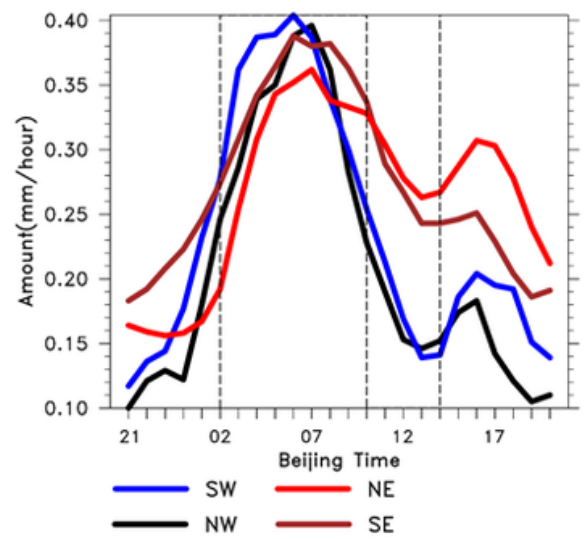

(b)

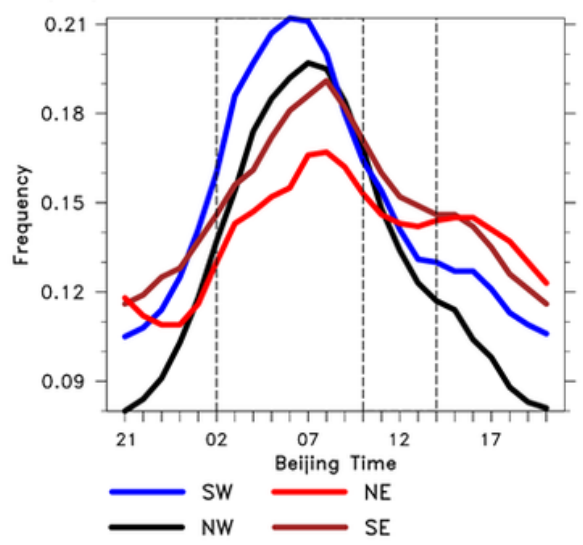

(c)

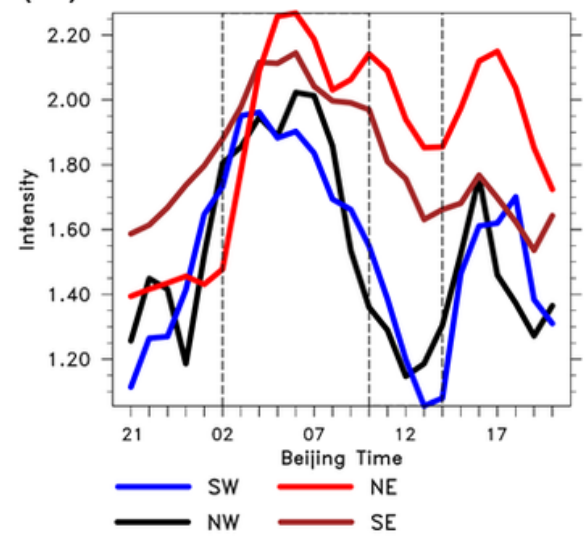

Figure 4 
Diurnal variations in warm season for the four regions rainfall (a) amount, (b) frequency and (c) intensity. The black dashed lines denote night (2100-0100 LST), early-morning (0200-1000 LST), noon (11001300 LST), and afternoon (1400-2000LST) period.
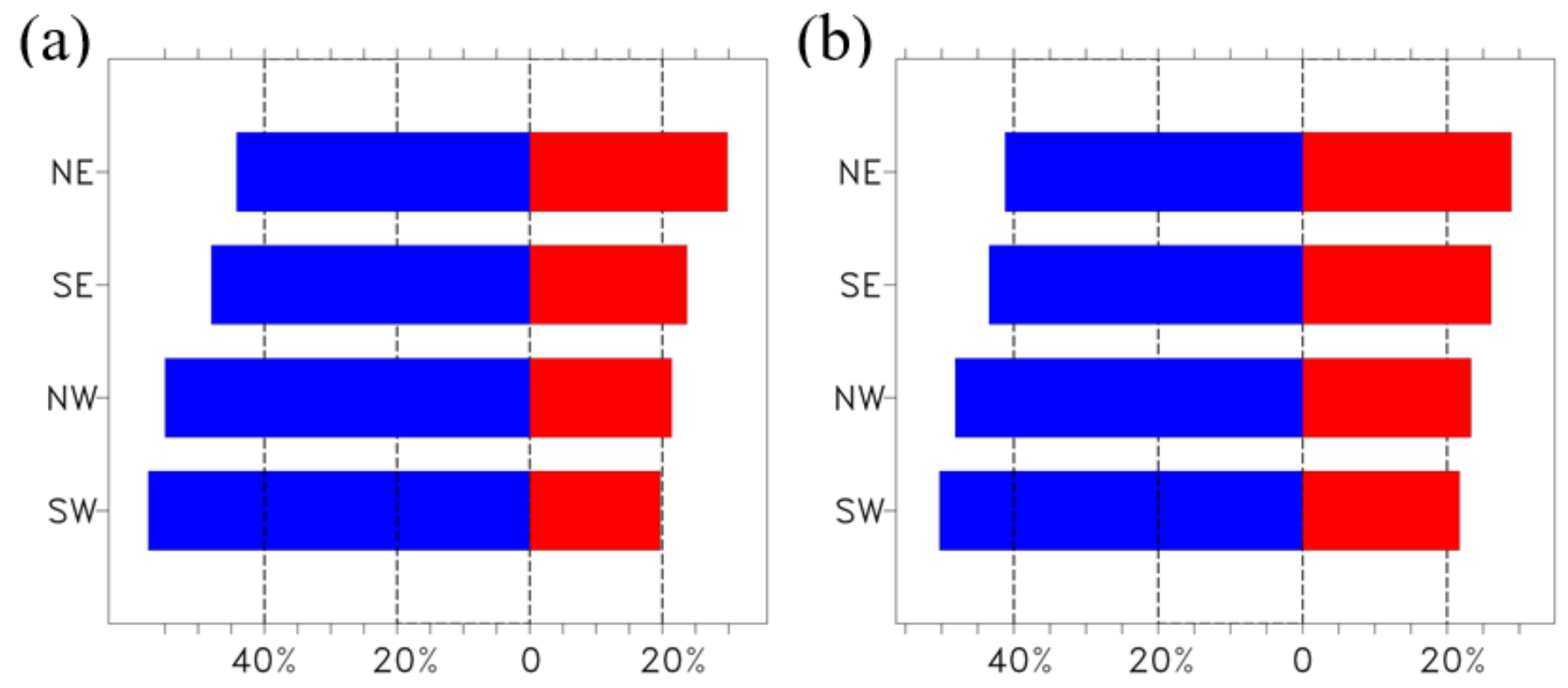

\section{Figure 5}

The proportions of rainfall (a) amount and (b) frequency in the early-morning (blue bars; \%) and lateafternoon (red bars; \%) period to their daily rainfall for the four regions. 


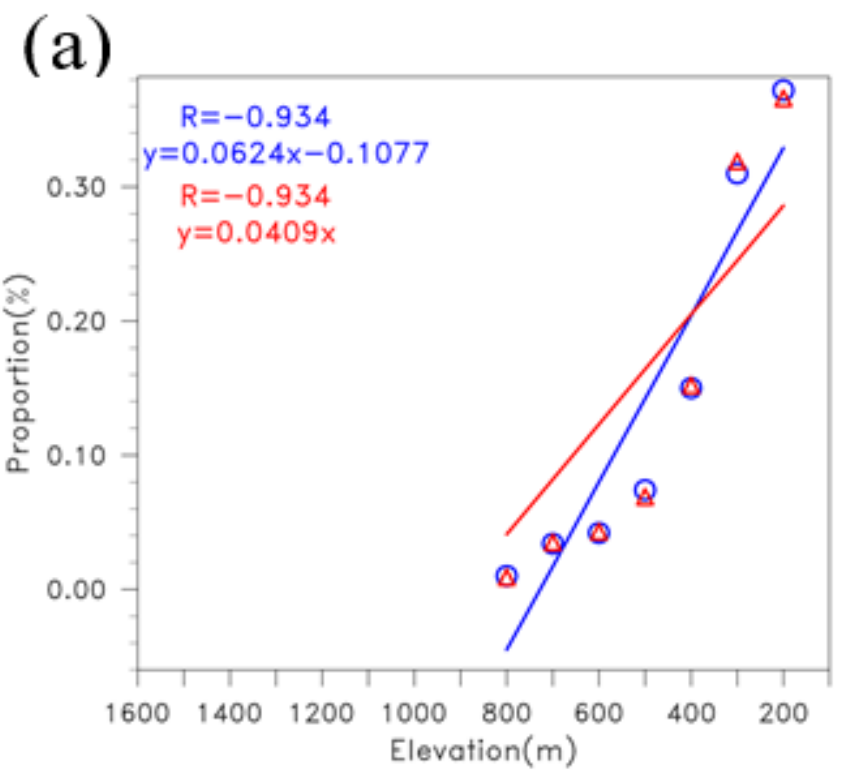

(c)

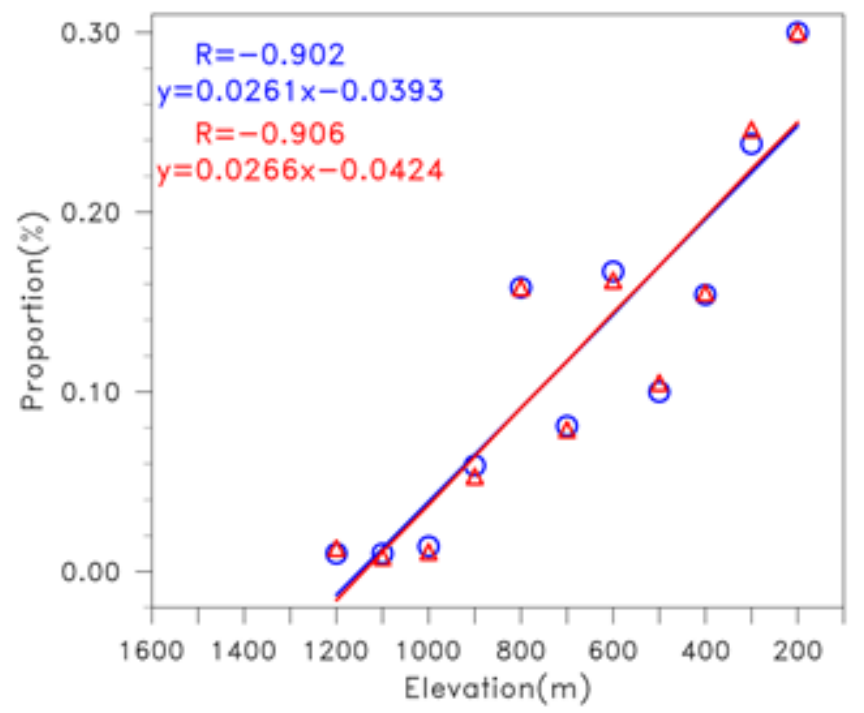

(b)

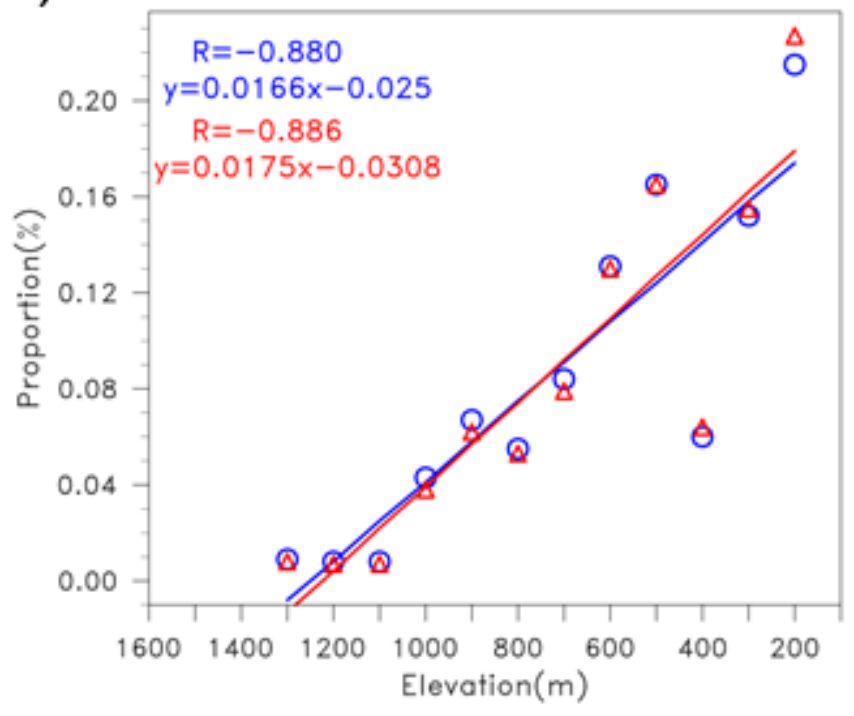

(d)

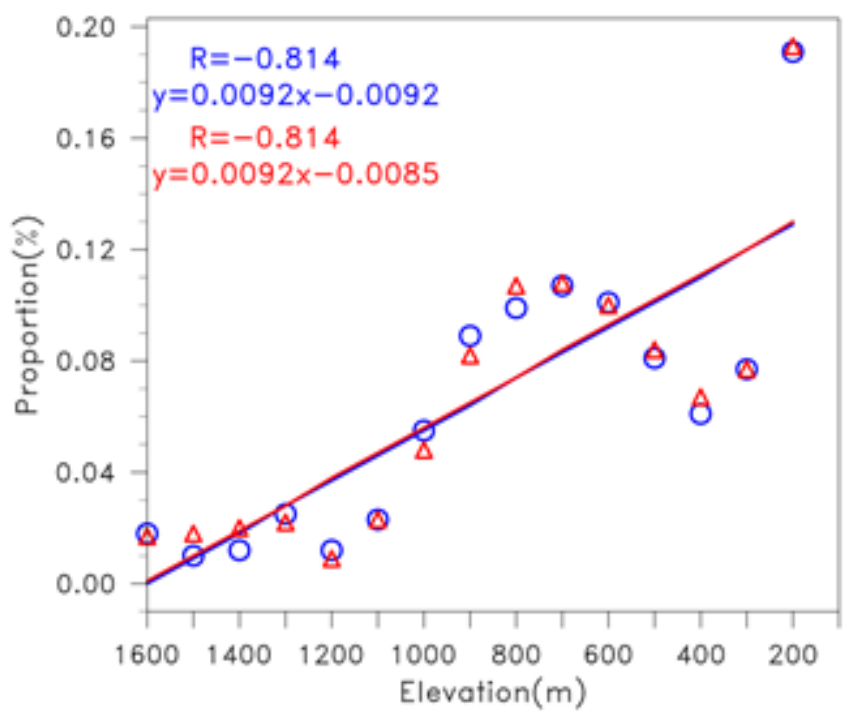

Figure 6

Relationships between the elevation and the proportion of early-morning rainfall frequency (blue) and amount (red) in (a) NW, (b) SW, (c) SE, (d) NE regions, the points represent the proportion values of earlymorning rainfall amount (frequency) to their daily rainfall within each $100 \mathrm{~m}$. The colored lines mean the linear fitting. 
(a)

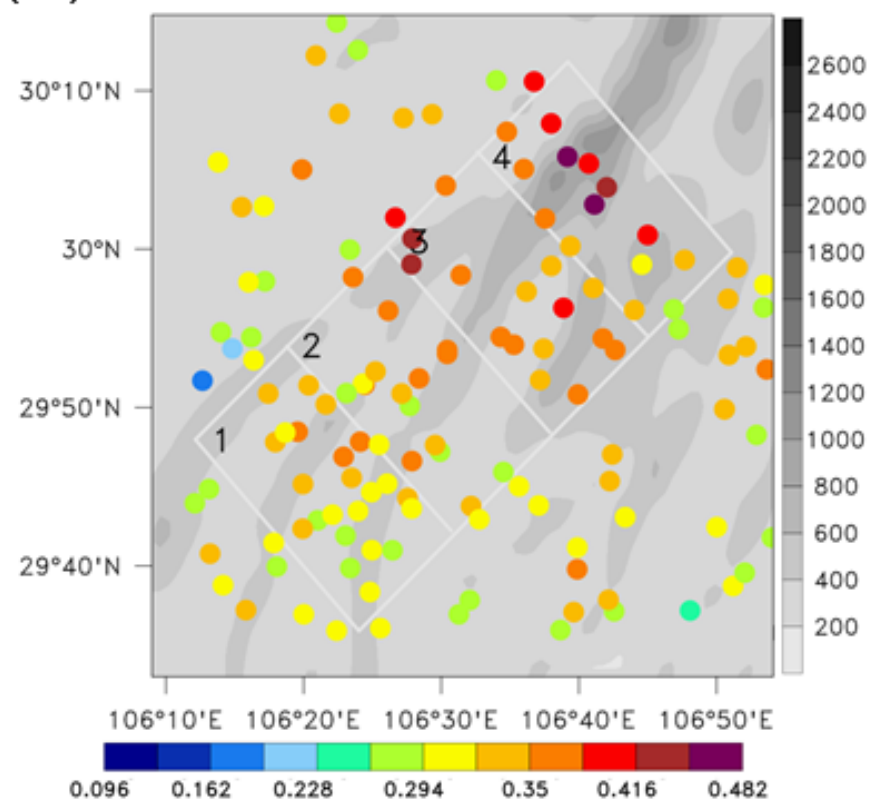

(c)

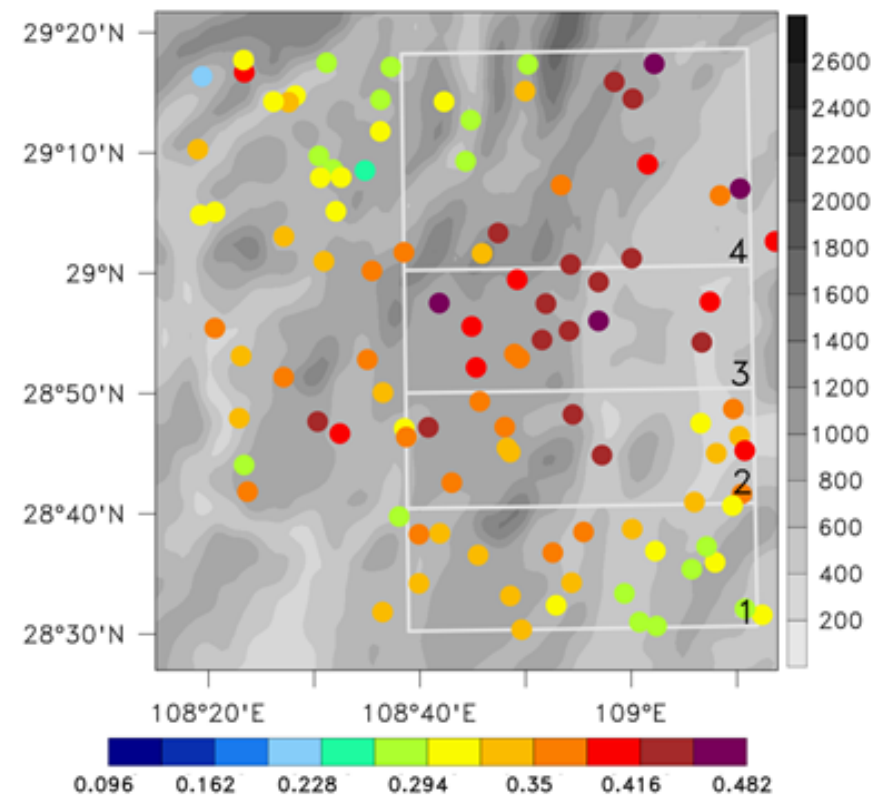

(b)

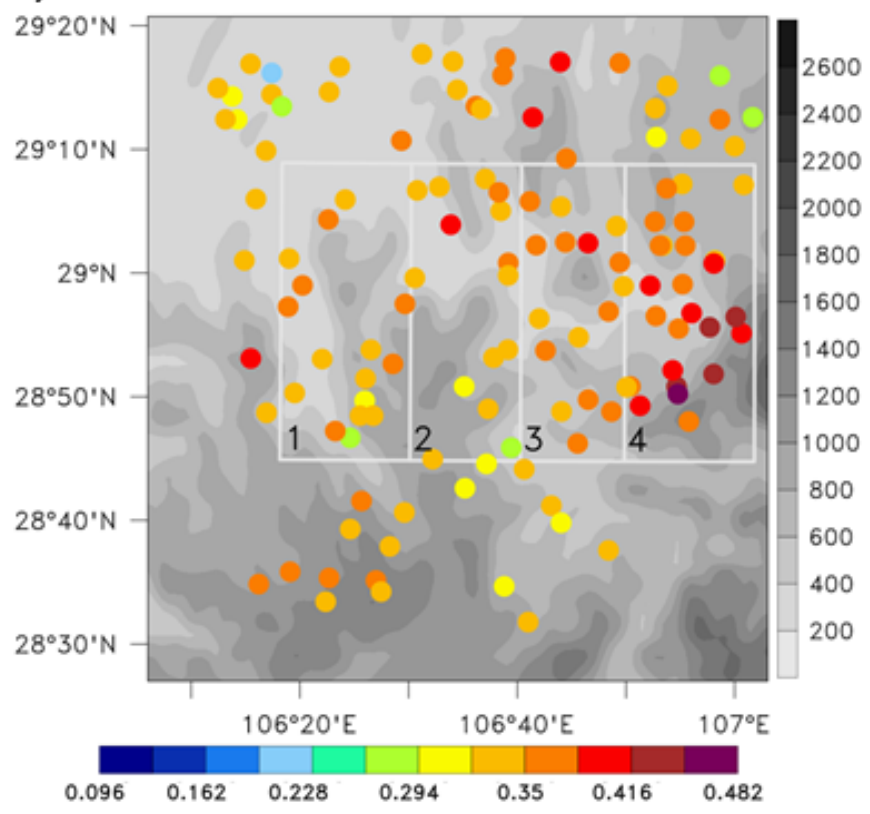

(d)

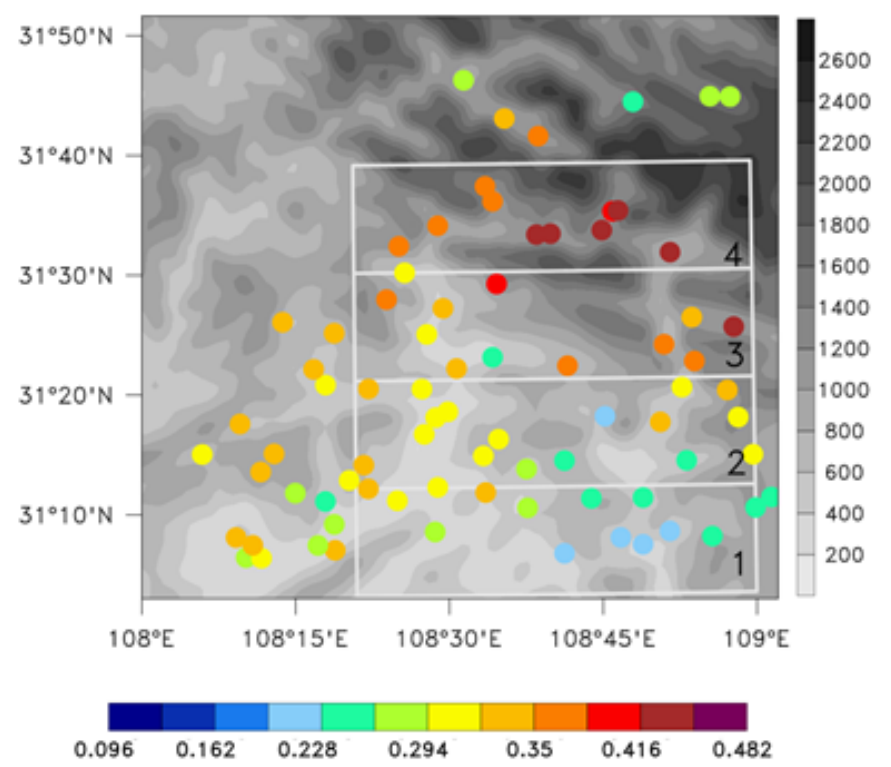

Figure 7

The spatial distribution of rainfall amount (units: $\mathrm{mm} \mathrm{h}-1$ ) in warm season during early-morning (02:0010:00 LST) in (a) NW, (b) SW, (c) SE, (d) NE regions. Grey solid lines (black numbers) outline the borders (label the number) of every sub-region. 
(a)

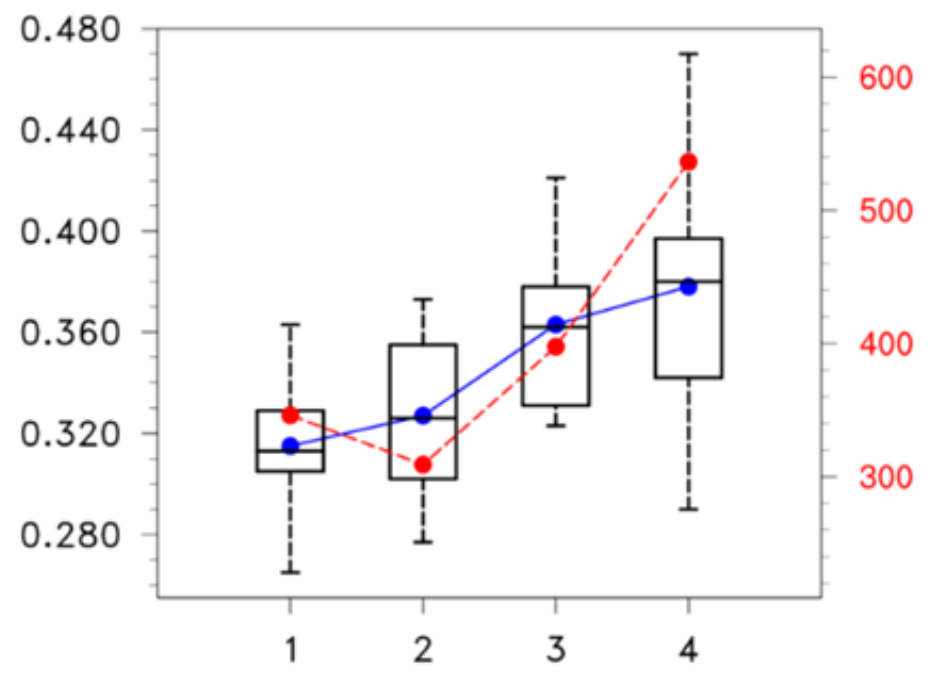

(c)
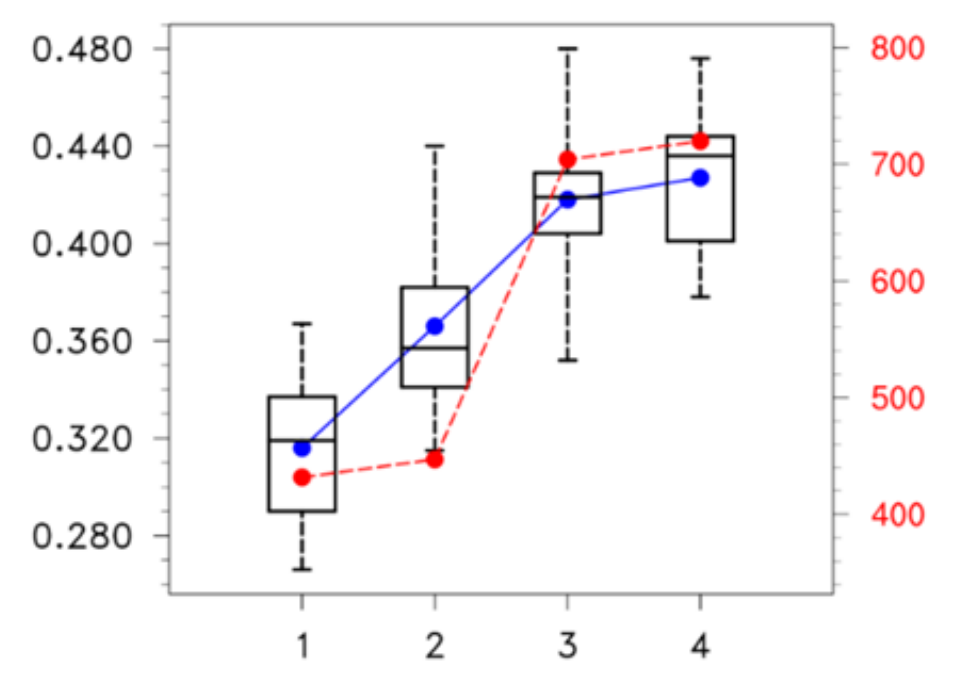

(b)

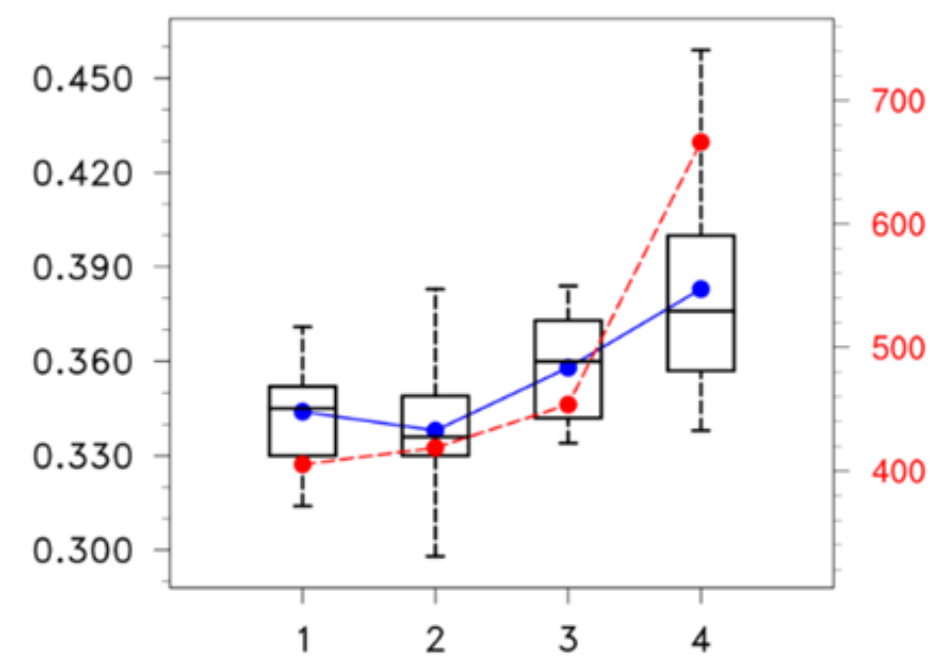

(d)

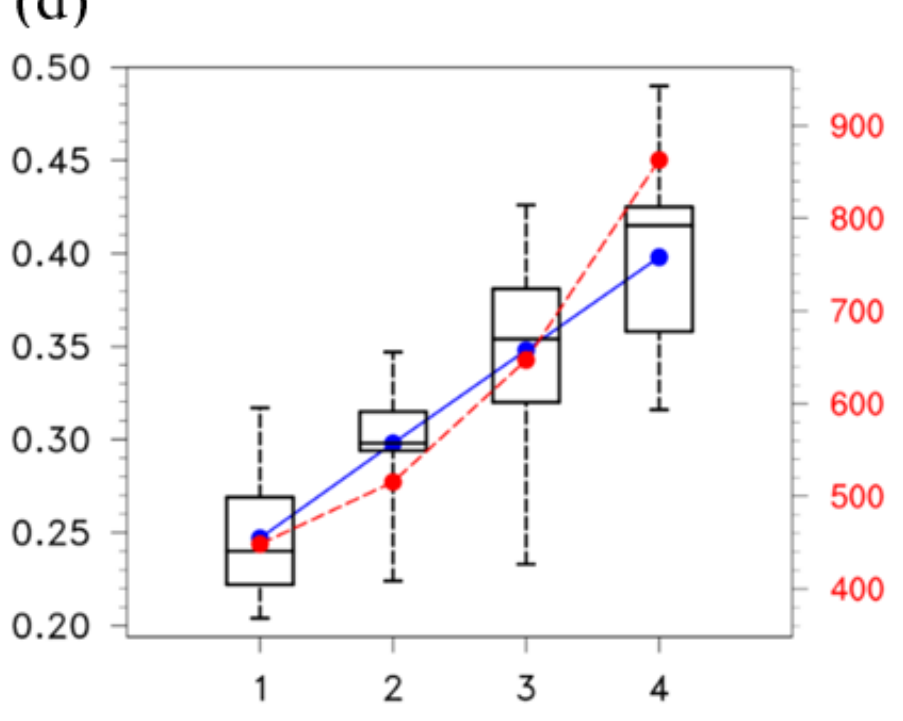

Figure 8

Boxplot of rainfall amount (units: mm h-1) during early-morning of (a) NW, (b) SW, (c) SE, (d) NE regions; box shows lower and upper quartiles. Black lines inside boxes represent medians. Blue dots are for data averages. Minimum and maximum values are shown by whiskers. Red line represents mean elevation (units: $\mathrm{m}$ ) of all stations. Labels 1, 2, 3, and 4 at bottom $\mathrm{x}$-axis represent four sub-regions in four study regions. The left $y$-axis label means rainfall amount scales and the right $y$-axis label indicates the elevation scales. 
(a)

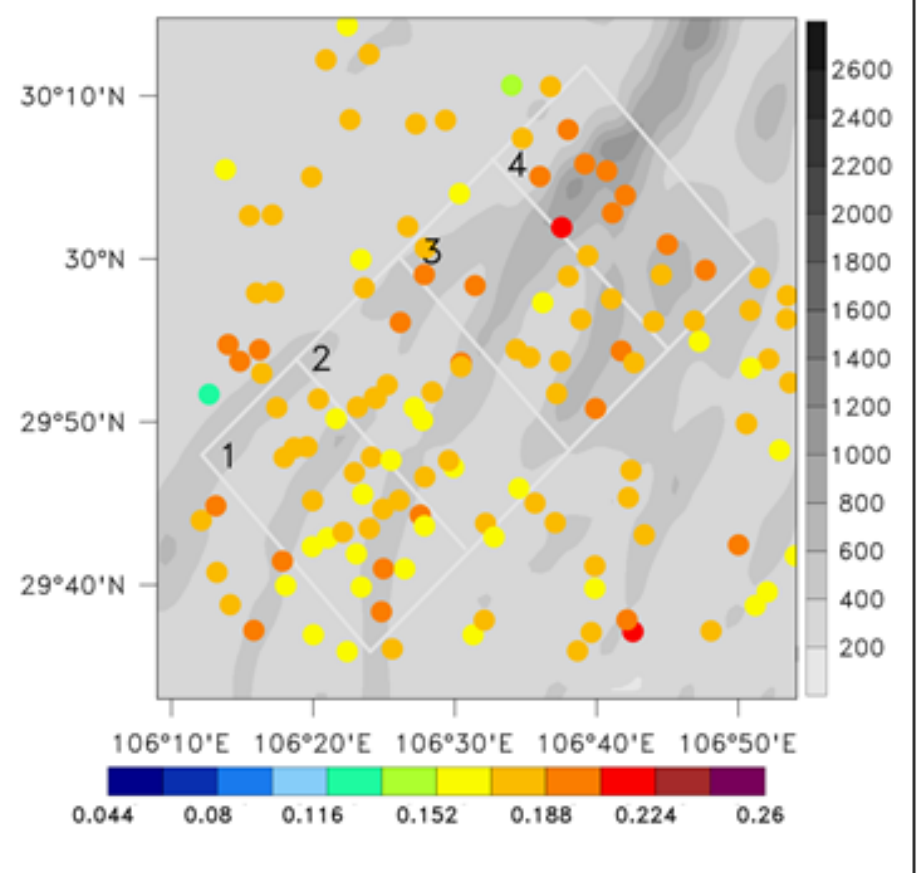

\section{(c)}

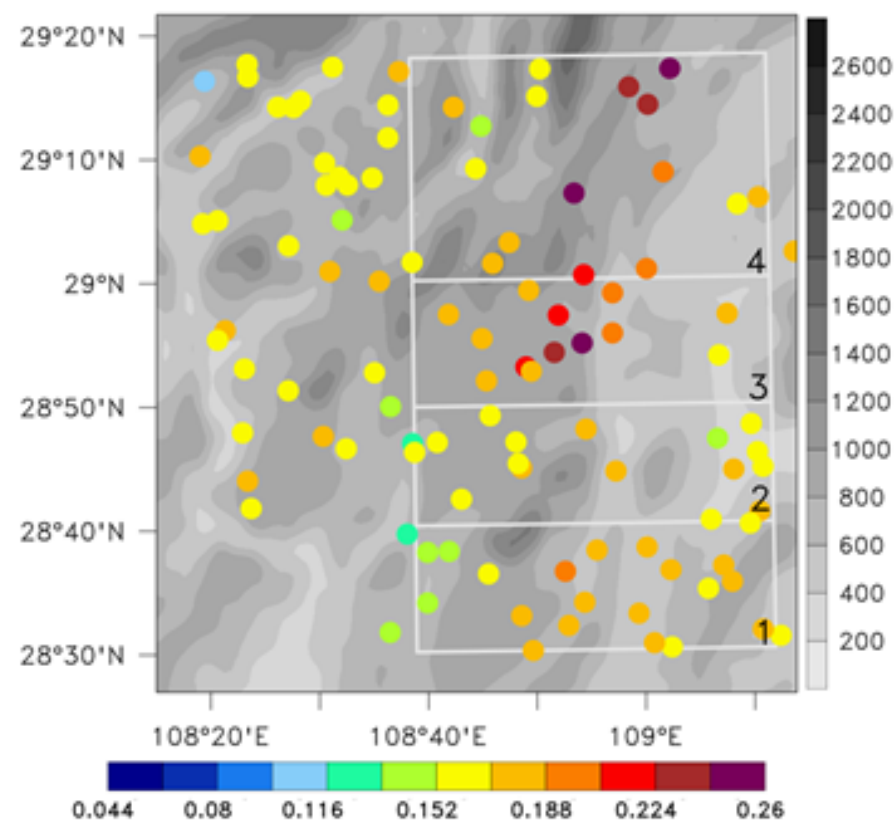

(b)

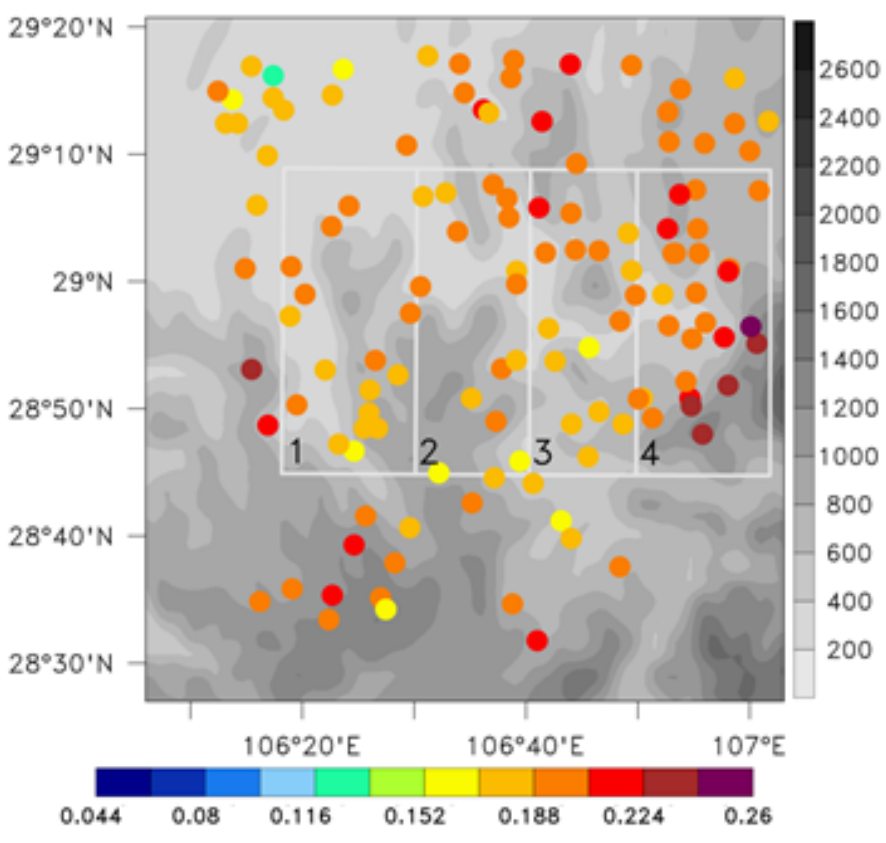

(d)

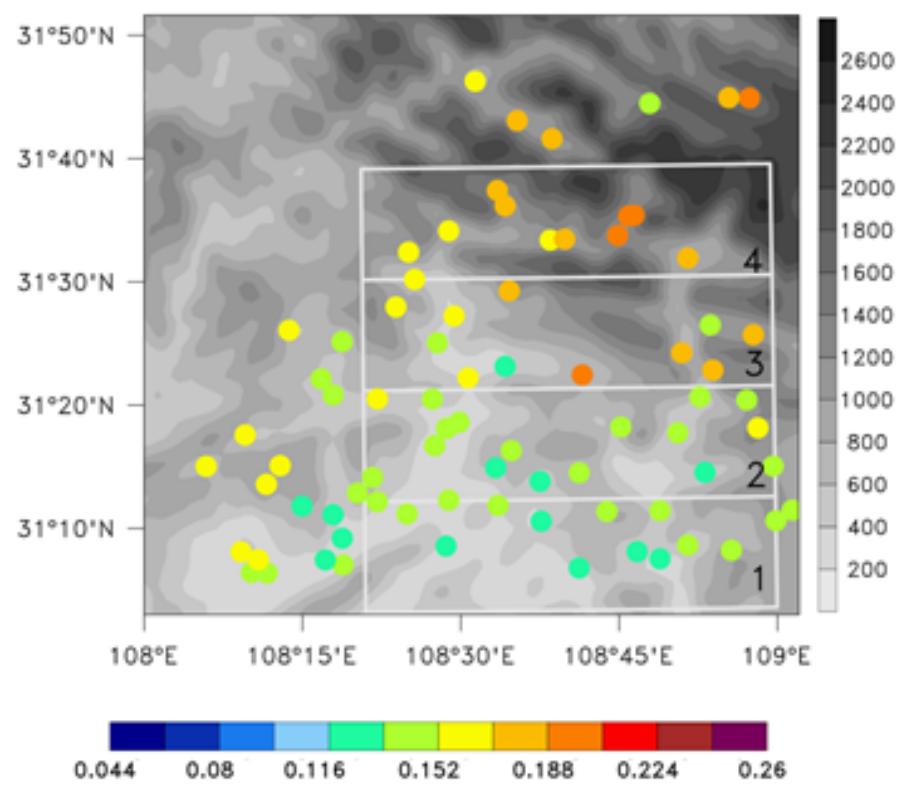

\section{Figure 9}

The same as fig.7, but for rainfall frequency. 
(a)

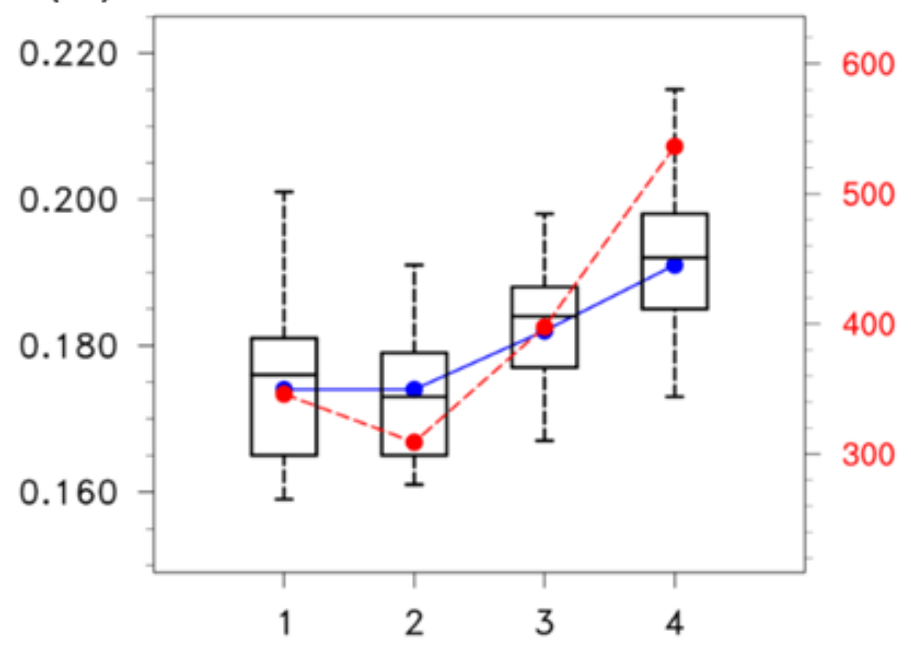

(c)

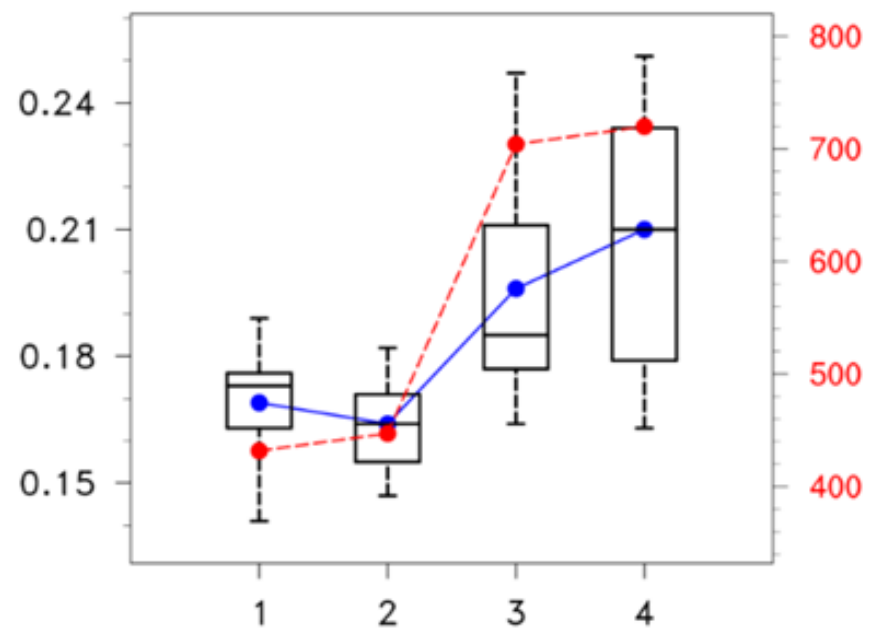

(b)

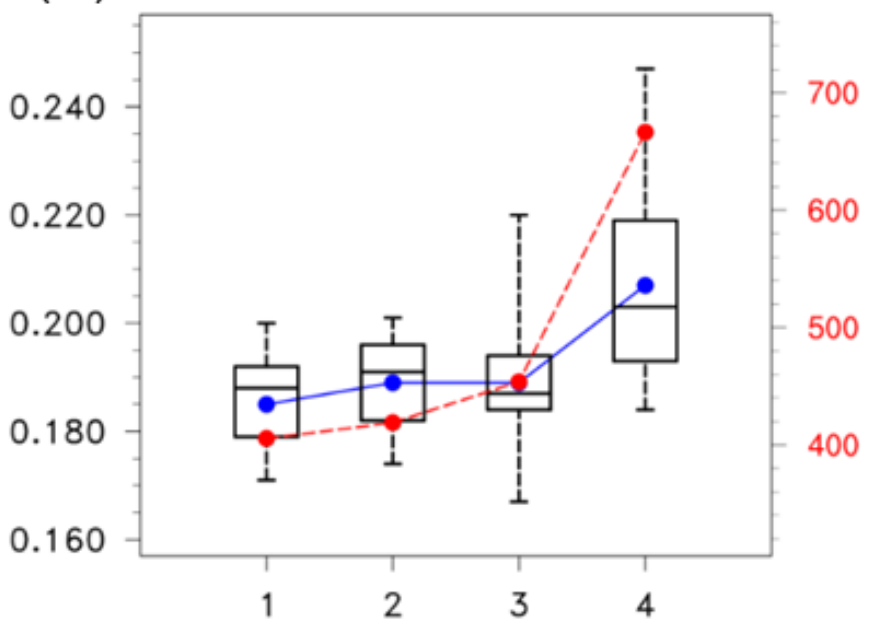

(d)

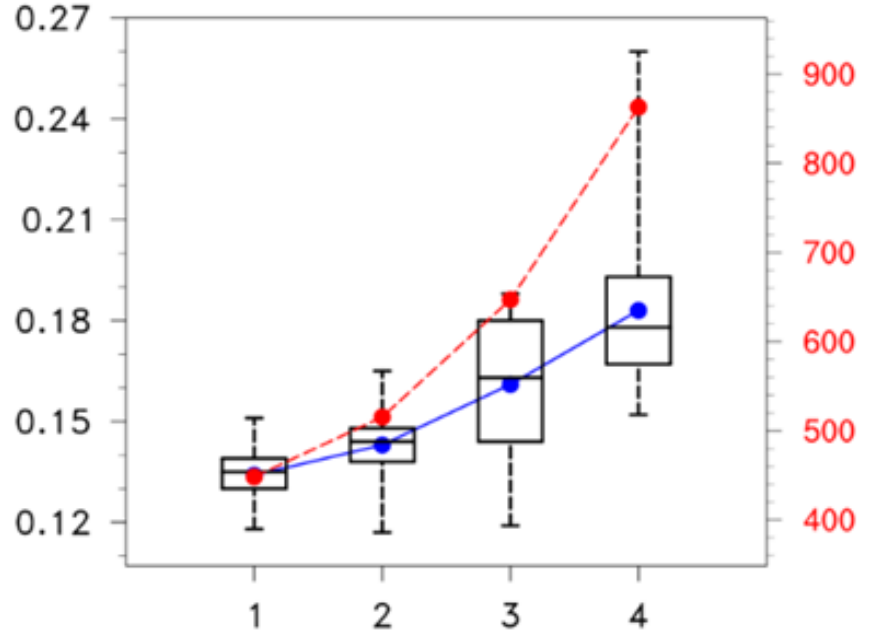

Figure 10

The same as fig.8, but for rainfall frequency. 
(a)

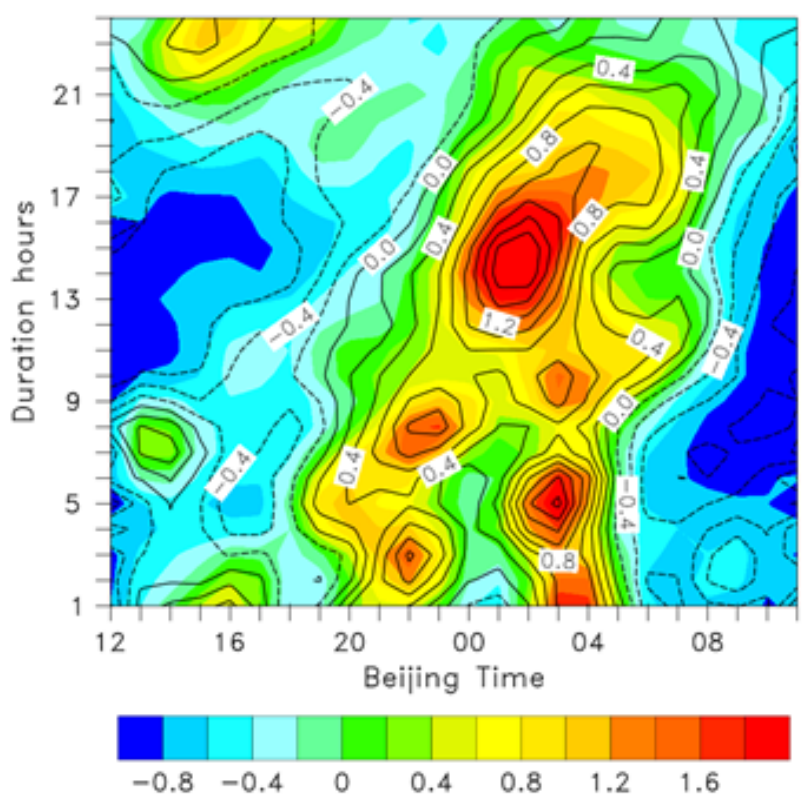

(c)
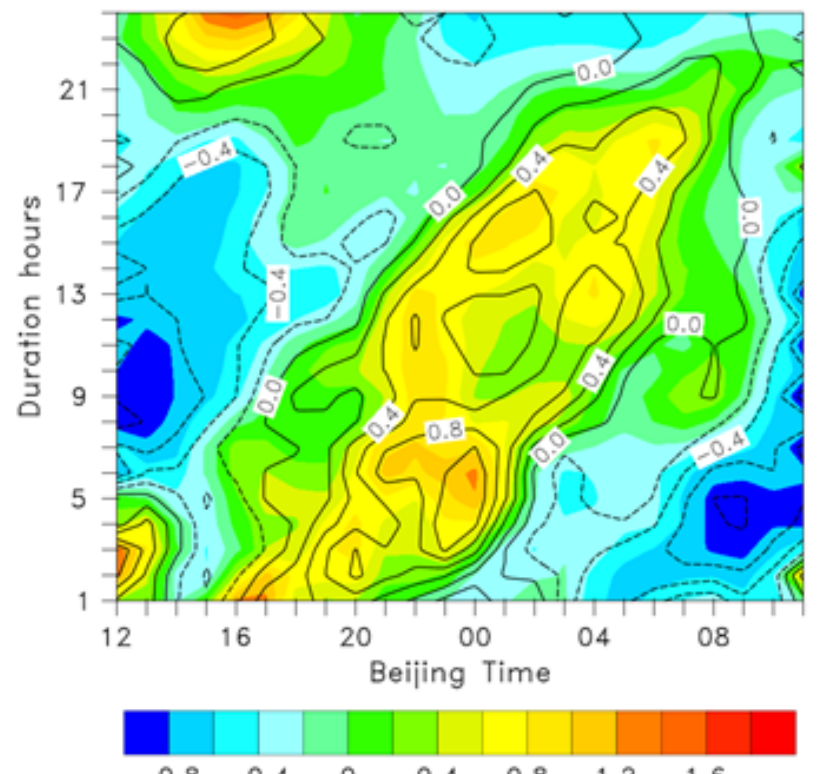

(b)
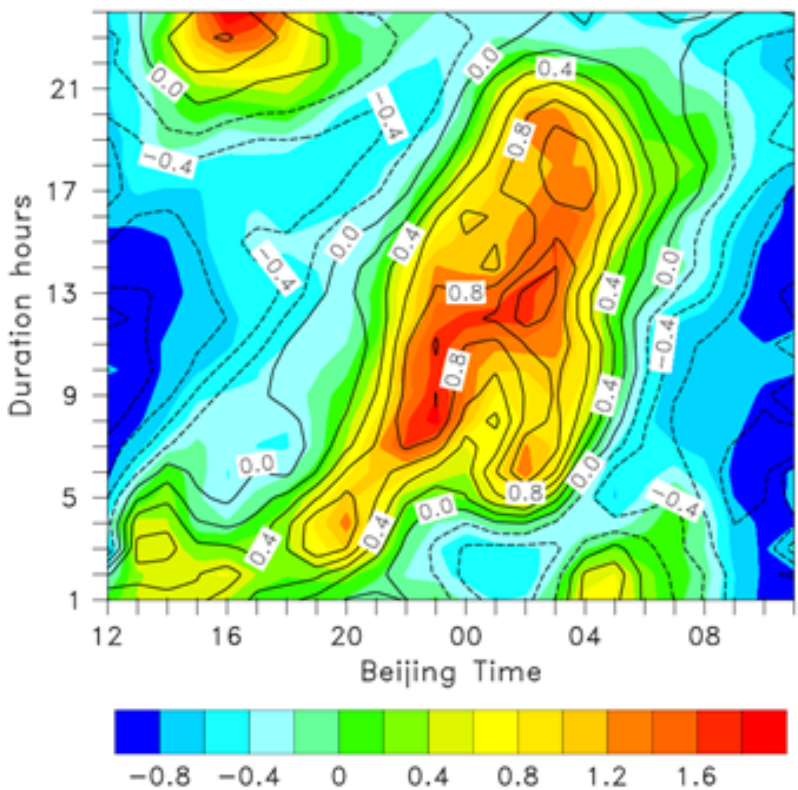

(d)

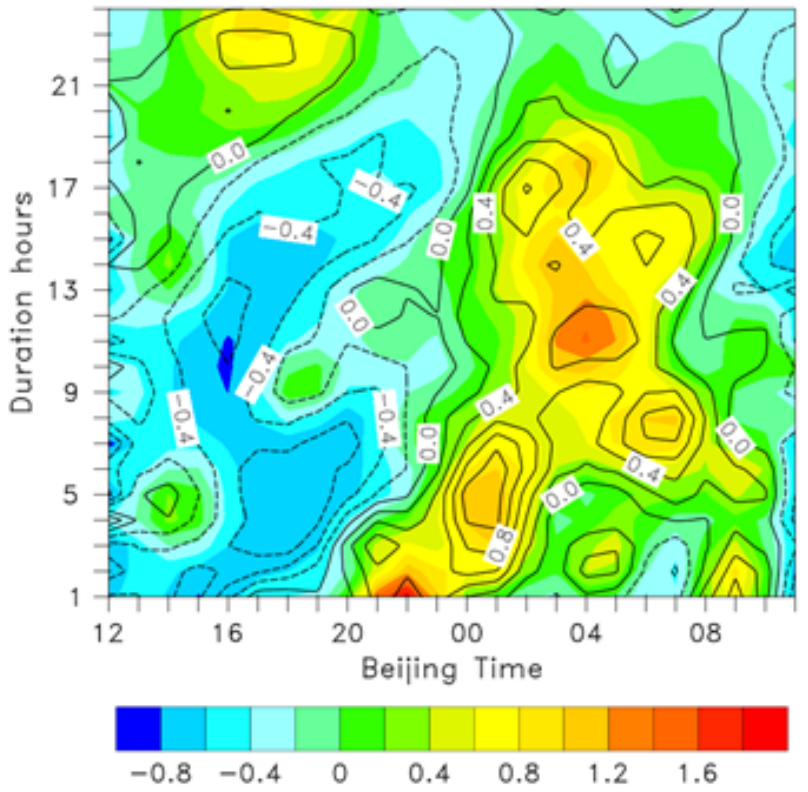

\section{Figure 11}

Diurnal cycle of rainfall events of rainfall amount (shaded) and frequency (contours) with change of different duration in (a) NW, (a) SW, (a) SE, and (c) NE. The rainfall amount and frequency is normalized by the daily mean for each duration time. 
(a)

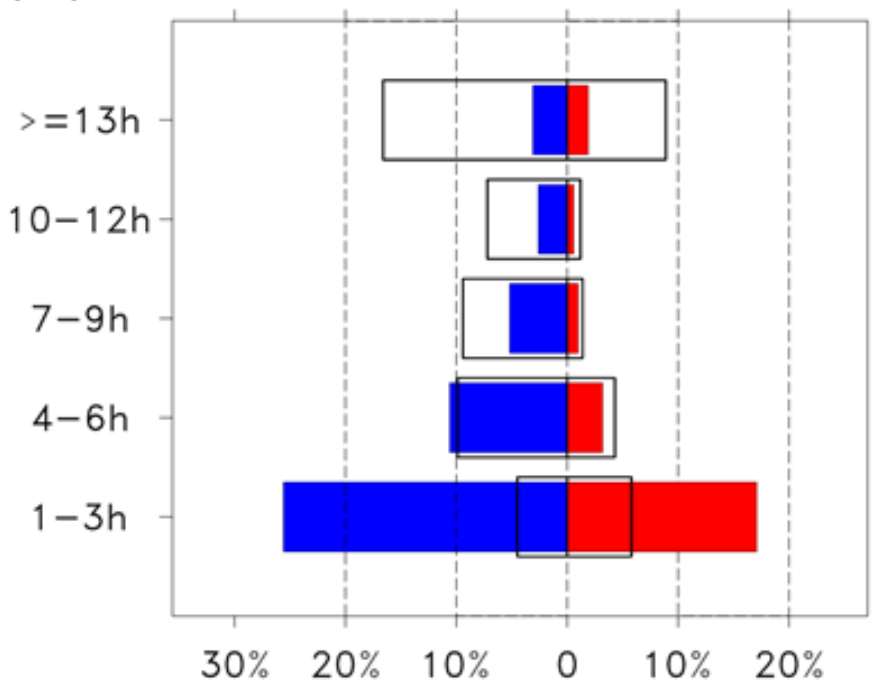

(c)

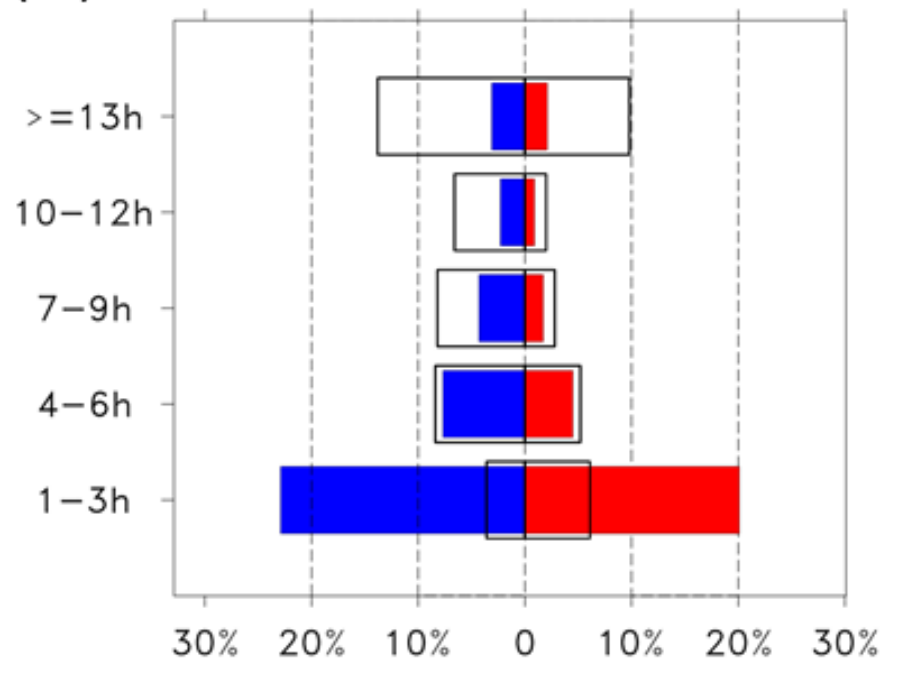

(b)

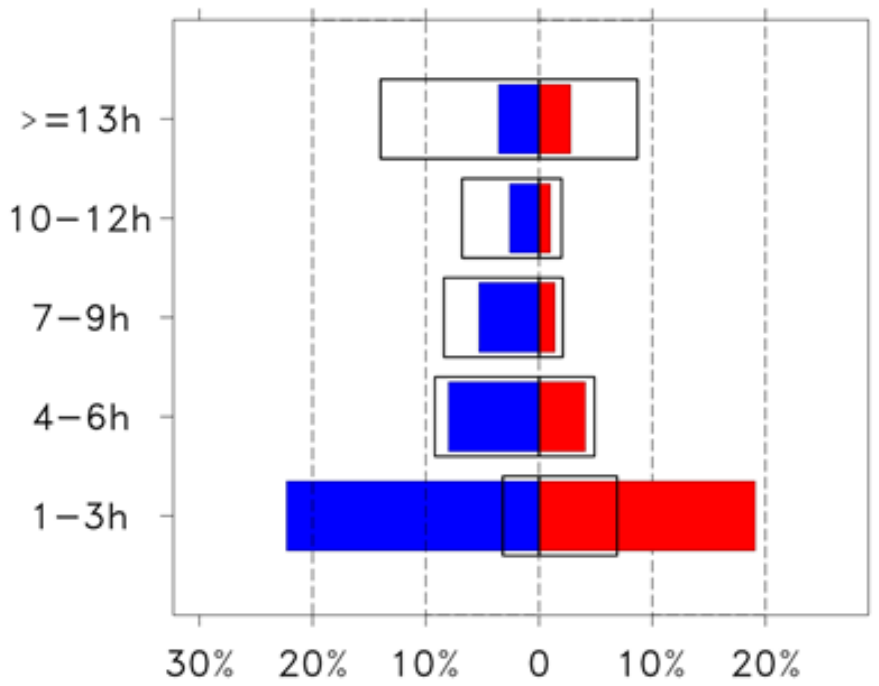

(d)

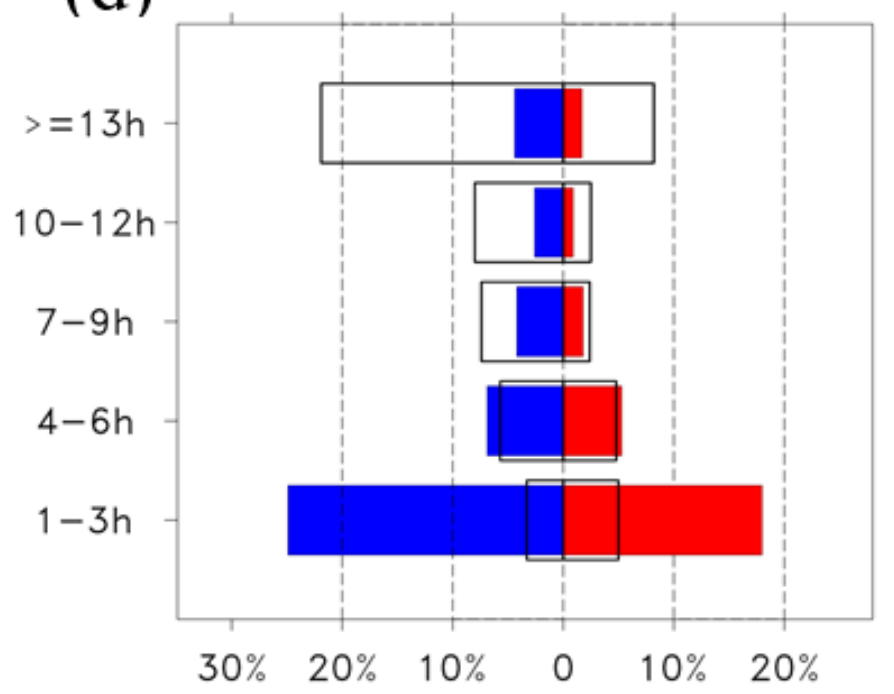

Figure 12

The proportions of rainfall amount (black rectangle; \%) and frequency (bar; \%) events during different durations to their daily rainfall events in the (a) NW, (a) SW, (a) SE, and (c) NE. The blue bars represent the proportion values of early-morning, and the red bars indicate late-afternoon periods. 
(a)

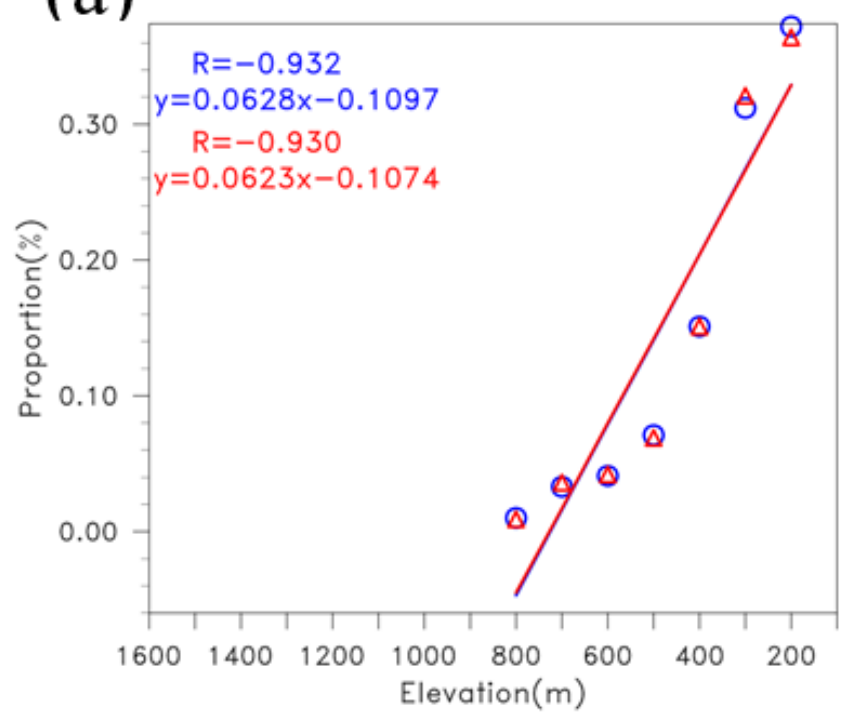

(c)

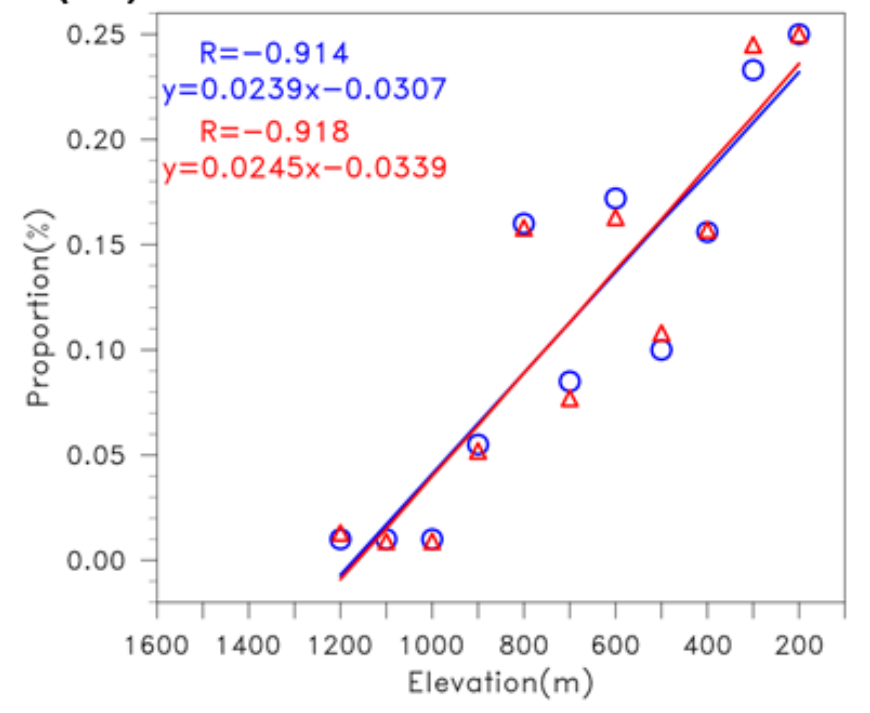

(b)

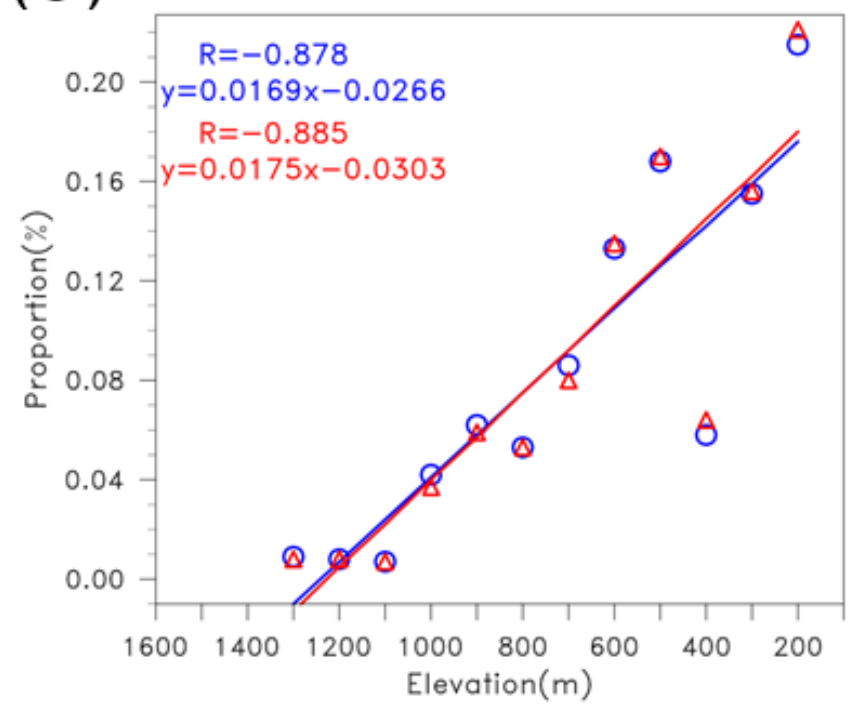

(d)

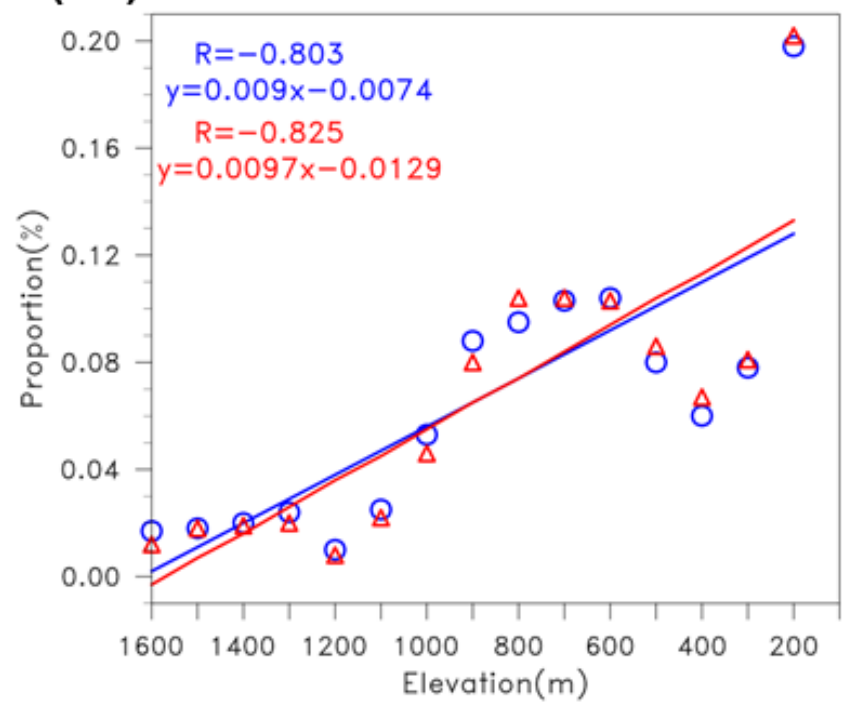

\section{Figure 13}

The same as Fig.6, but for the proportion of early-morning rainfall maximum frequency (blue) and amount (red) to their daily rainfall events in (a) NW, (b) SW, (c) SE, (d) NE regions. 